\title{
FILIAL THERAPY WITH PARENTS OF CHILDREN EXPERIENCING LEARNING DIFFICULTIES
}

\section{DISSERTATION}

\author{
Presented to the Graduate Council of the \\ University of North Texas in Partial \\ Fulfillment of the Requirements
}

For the Degree of

DOCTOR OF PHILOSOPHY

By

Amy L. Kale, B.A., M.A. Ed.

Denton, Texas

August, 1997 


\section{Kale, Amy L., Filial Therapy with Parents of Children Experiencing} Learning Difficulties, Doctor of Philosophy (Counseling and Student Services), August 1997, 141 pp., 28 tables, references, 100 titles.

This study was designed to determine the effectiveness of the Landreth 10-week filial therapy model as an intervention for the parents of children experiencing learning difficulties. Filial therapy is an approach used by play therapists to train parents to be therapeutic agents with their own children. Parents are taught basic child-centered play therapy skills and practice those skills during weekly play sessions with their children. The purpose of this study was to determine if filial therapy is effective in: 1) increasing parental acceptance of children with a learning difficulty; 2) reducing the stress level of parents of children with learning difficulties; 3) decreasing social problems and total behavior problems of children with learning difficulties as reported by parents and teachers.

The experimental group parents $(\mathrm{N}=11)$ received 10 weekly 2 hour filial therapy training sessions and participated in weekly 30 -minute play sessions with one of their children. The control group $(\mathrm{N}=11)$ received no treatment during the 10 weeks. All adult participants completed the Porter Parental Acceptance Scale, the Parenting Stress Index, and the Child Behavior Checklist Parent Report Form. The teachers of the child participants completed the Child 
Behavior Checklist Teacher Report Form.

Analyses of Covariance revealed that the parents of children experiencing learning difficulties in the experimental group significantly increased their attitude of acceptance toward their children and experienced a significant decrease in the level of stress related to parenting. There was not a significant decrease in social problems and total behavior problems as reported by parents and teachers.

This study supports filial therapy as an effective intervention for the parents of experiencing learning difficulties. Filial therapy equips parents with healthy parenting skills and knowledge which significantly reduces parental stress and increases parental acceptance. Thus, filial therapy offers significant possibilities for promoting the parent-child relationship and the well-being of children experiencing learning difficulties. 


\title{
FILIAL THERAPY WITH PARENTS OF CHILDREN EXPERIENCING LEARNING DIFFICULTIES
}

\section{DISSERTATION}

\author{
Presented to the Graduate Council of the \\ University of North Texas in Partial \\ Fulfillment of the Requirements
}

For the Degree of

DOCTOR OF PHILOSOPHY

By

Amy L. Kale, B.A., M.A. Ed.

Denton, Texas

August, 1997 
Copyright by

Amy L. Kale 1997 


\section{ACKNOWLEDGMENTS}

I gratefully acknowledge the Ponder Independent School District and the Aubrey Independent School District for granting permission for this research to be conducted in their school systems. 


\section{TABLE OF CONTENTS}

Chapter

I. INTRODUCTION $\ldots \ldots \ldots \ldots \ldots \ldots \ldots \ldots \ldots \ldots \ldots \ldots \ldots \ldots$ 1

Statement of the Problem $\ldots \ldots \ldots \ldots \ldots \ldots \ldots \ldots \ldots \ldots \ldots$

Synthesis of Related Literature $\ldots \ldots \ldots \ldots \ldots \ldots \ldots \ldots \ldots \ldots \ldots$

Parental Acceptance . . . . . . . . . . . . . . . . . 8 8

Filial Therapy ......................... 10

Parenting Children with Learning Difficulties . . . . . . . . 23

Summary ............................. 25

II. METHODS AND PROCEDURES $\ldots \ldots \ldots \ldots \ldots \ldots \ldots \ldots \ldots \ldots \ldots \ldots$

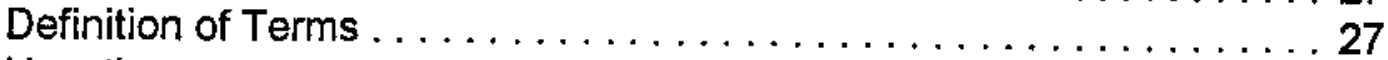

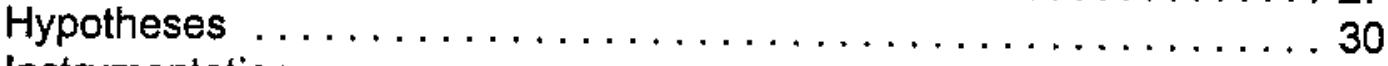

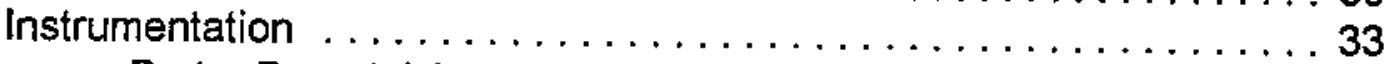

Porter Parental Acceptance Scale $\ldots \ldots \ldots \ldots \ldots \ldots \ldots . . \ldots . \ldots 33$

Parenting Stress Index . . . . . . . . . . . . . . 34

Parent Report Form of the Child Behavior Checklist . . . . . . 35

The Child Behavior Checklist Teacher Report Form . . . . . . 37

Selection of Participants $\ldots \ldots \ldots \ldots \ldots \ldots \ldots \ldots \ldots \ldots \ldots, \ldots \ldots$

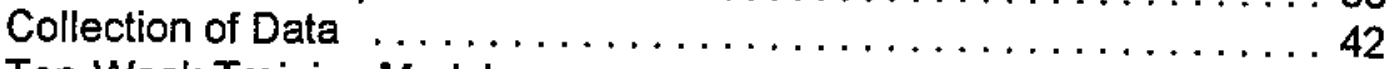

Ten-Week Training Model $\ldots \ldots \ldots \ldots \ldots \ldots \ldots \ldots \ldots \ldots, \ldots \ldots$

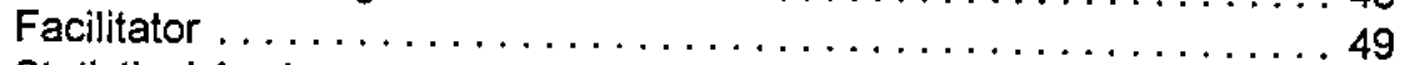

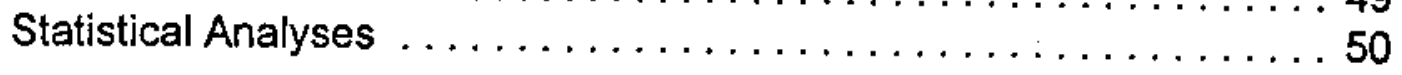

III. RESULTS AND DISCUSSION $\ldots \ldots \ldots \ldots \ldots \ldots \ldots \ldots \ldots \ldots \ldots$

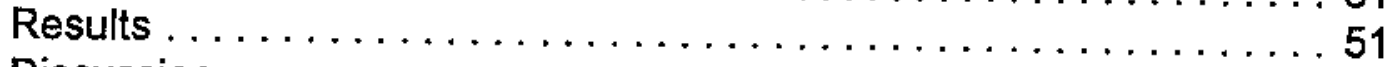

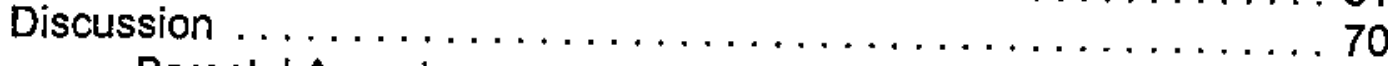

Parental Acceptance ......................... 70

Parental Stress $\ldots \ldots \ldots \ldots \ldots \ldots \ldots \ldots \ldots \ldots \ldots \ldots . \ldots \ldots 71$

Problematic Behaviors of Children with Learning Difficulties ...73

Recommendations ....................... 76

Concluding Remarks $\ldots \ldots \ldots \ldots \ldots \ldots \ldots \ldots \ldots \ldots \ldots \ldots \ldots \ldots 77$

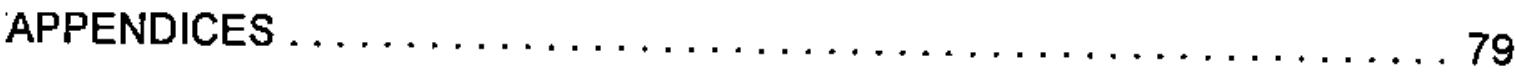

A: Parenting Class Information And Consent Forms . . . . . . . 79

B: Letters of Permission From Participating Schools $\ldots \ldots \ldots \ldots \ldots \ldots 83$ 
C: Marketing Materials $\ldots \ldots \ldots \ldots \ldots \ldots \ldots \ldots \ldots \ldots \ldots, \ldots \ldots$

D: Child Data Sheet . . . . . . . . . . . . . . . . . . . 92

E: Letter of Permission to use Porter Parental Acceptance Scale . . . . . 98

F: Porter Parental Acceptance Scale . . . . . . . . . . . . . . 100

G: Filial Therapy Training Session Outlines And Handouts . . . . 108

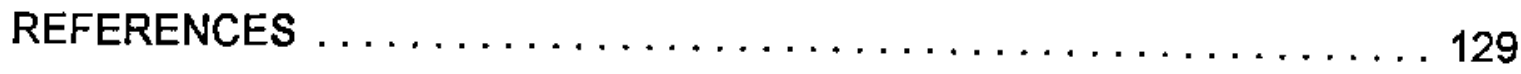




\section{LIST OF TABLES}

Table

Page

1. Mean total scores for the Porter Parental Acceptance Scale (PPAS) . . 52

2. Analysis of covariance data for the mean total scores for the (PPAS) .52

3. Mean scores for the (PPAS) subscale: Respect for the child's feelings and right to express them $\ldots \ldots \ldots \ldots \ldots \ldots \ldots \ldots \ldots \ldots \ldots \ldots$

4. Analysis of covariance data for the mean scores on the (PPAS) subscale: Respect for the child's feelings and right to express them $\ldots \ldots \ldots 53$

5. Mean scores for the (PPAS) subscale: Appreciation of the child's unique makeup $\ldots \ldots \ldots \ldots \ldots \ldots \ldots \ldots \ldots \ldots \ldots \ldots \ldots \ldots$

6. Analysis of covariance data for the mean scores on the (PPAS) subscale: Appreciation of the child's unique makeup $\ldots \ldots \ldots \ldots \ldots \ldots \ldots 5$

7. Mean scores for the (PPAS) subscale: Recognition of the child's need for autonomy and independence $\ldots \ldots \ldots \ldots \ldots \ldots \ldots \ldots \ldots$

8. Analysis of covariance data for the mean scores on the (PPAS) subscale: Recognition of the child's need for autonomy and independence . . . . 56

9. Mean scores for the (PPAS) subscale: Unconditional love . . . . . 57

10. Analysis of covariance data for the mean scores on the(PPAS) subscale: Unconditional love $\ldots \ldots \ldots \ldots \ldots \ldots \ldots \ldots \ldots \ldots \ldots \ldots 7$

11. Mean scores for the Parenting Stress Index (PSI) . . . . . . . . 58

12. Analysis of covariance data for the mean scores for the (PSI) . . . . 59

13. Mean scores for the (PSI) subscale: Parent domain $\ldots \ldots \ldots \ldots 60$

14. Analysis of covariance data for the mean scores for the (PSI) subscale:

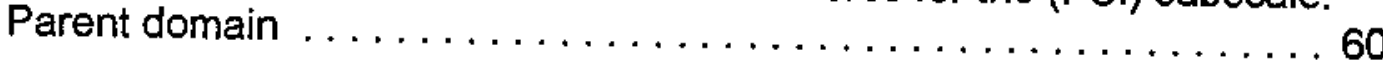


15. Mean scores for the (PSI) subscale: Child domain $\ldots \ldots \ldots \ldots 61$

16. Analysis of covariance data for the mean scores for the (PSI) subscale: Child domain $\ldots \ldots \ldots \ldots \ldots \ldots \ldots \ldots \ldots \ldots \ldots \ldots \ldots \ldots$

17. Mean scores for externalizing behavior problems on the parent report form of the Child Behavior Checklist

18. Analysis of covariance data for the mean scores on externalizing behavior problems on the parent report form of the Child Behavior Checklist .. 63

19. Mean scores for internalizing behavior problems on the parent report form of the Child Behavior Checklist ................... 64

20. Analysis of covariance data for the mean scores on internalizing behavior problems on the parent report form of the Child Behavior Checklist ... 64

21. Mean scores for total behavior problems on the parent report form of the Child Behavior Checklist

22. Analysis of covariance data for the mean scores for total behavior problems on the parent report form of the Child Behavior Checklist ...65

23. Mean scores for externalizing behavior problems on the teacher report form of the Child Behavior Checklist

24. Analysis of covariance data for the mean scores on externalizing behavior problems on the teacher report form of the Child Behavior Checklist . . 67

25. Mean scores for internalizing behavior problems on the teacher report form of the Child Behavior Checklist

26. Analysis of covariance data for the mean scores on internalizing behavior problems on the teacher report form of the Child Behavior Checklist . 68

27. Mean scores for total behavior problems on the teacher report form of the Child Behavior Checklist

28. Analysis of covariance data for the mean scores for total behavior problems on the teacher report form of the Child Behavior Checklis 


\section{CHAPTER I}

\section{INTRODUCTION}

Parenting is a challenging task and parenting a child who is experiencing difficulties with learning exacerbates that challenge. Most children are not formerly diagnosed with a learning difficulty until they enter school (Barkley, 1990; O'Hara \& Levy, 1984). Although parents may have noticed that their child's development was somehow different from other children and sought help or advice from a variety of sources, they have been most often told that nothing is wrong because the child looks normal (O'Hara \& Levy, 1984). Parents often respond to this advice by adjusting to their child's behavior and beginning to perceive it as normal (Willner \& Crane, 1979). When school problems begin and persist, parents must again look for reasons or causes and this search often renews emotions of uncertainty and alarm.

The problems of children with learning difficulties are not physically visible and therefore, not readily recognized by parents and society. Often during infant and preschooler years, children with learning difficulties are irritable, overly active, and give little positive feedback to the parent. Family members have often reacted adversely to these behaviors before it was apparent the child had impairments, thus leading to later feelings of 
responsibility and guilt. Families also often experience frustration and guilt as a result of repeated behavioral or learning problems evidenced by the child (Faerstein, 1981). Parents report feeling helpless when their apparently normal child displays such school-related problems as sadness, anger, frustration, sleeplessness, poor self-esteem, mood swings, and unfounded aches and pains (L. S. Gallagher, 1995). When a child is finally identified as having a learning difficulty, there is often a welcomed relief from the early experiences of indecision, frustration, and fear. However, with the diagnosis there also comes the realization that the definition and treatment of learning difficulties is ambiguous and the advice from various experts is often contradictory. Parents often oscillate among the various explanations and treatment plans presented to them or reject recommendations and retreat into denial (Faerstein, 1981). Such ambiguity prolongs and complicates the parents' process of mourning over the loss of their hopes and dreams for a "perfect child" (Anderegg, Vergason, and Smith, 1992; Kaslow \& Cooper, 1978).

The presence of learning difficulties can predispose children and parents to stress. For children who do not meet age appropriate norms socially or academically but look perfectly normal, public intolerance of the inability to live up to expectations compounds the difficulties and adds to the stress experienced by the family (O'Hara \& Levy, 1984). When a child's problem is diagnosed, the family typically has to undergo additional changes in adjusting their perceptions of, and aspirations for, the child. The family's balance and patterns are 
disrupted, and often the child is viewed as the source and cause of family and marital problems (Kaslow \& Cooper, 1978; Wright, Matlock, \& Matlock, 1985).

This negative perception parents often have of children with learning difficulties is also reflected in their attitudes about their child's personal characteristics. Parents of children with learning difficulties view their children more negatively than do parents of normal children on their perception of their children's consideration of others, ability to receive affection, clingingness, tendencies to be rigid, general negativism, physical coordination, and fatigability (Strag, 1972). Boersma \& Chapman (1979) found that mothers of children experiencing learning difficulties reported significantly more negative interaction with their children, significantly less positive reactions to their children's school behavior, and expected their children to perform less well on future academic tasks than did mothers of normally achieving children. A significant concern is that parents of children with learning difficulties may become so frustrated and perceptually biased that they quit trying to help their children achieve academically, thus setting up a self-fulfilling prophecy of failure for the children.

Parents' perceptions of themselves and the parent-child relationship are also effected by having a child with learning difficulties. Parents of children with learning difficulties find that techniques that worked with other children may not be effective with the child with learning difficulties and often have difficulty sorting out behaviors that are misbehaviors and behaviors that result from the learning difficulty (Zuckerman \& Zuckerman, 1982). Research indicates that 
parents perceive children with learning difficulties as having behavioral characteristics that make their parenting role more difficult. As a result, parents may have attitudes and behaviors that contribute to their children's negative selfperceptions and misbehavior (Latson, 1986).

Many studies point to the need for parent education and/or counseling for parents and children experiencing learning difficulties (A. P. Turnbull and Turnbull, 1990; Eiserman, Weber, and McCoun, 1995; Mercer, 1997; Reynolds, Wang, and Walberg, 1992). Among the reasons for the suggestion of counseling and education for parents, and counseling for the children are stress, self-concept, and social/behavioral problems. All parents experience some level of stress related to the growth, development, and success of their children, but for the parents of children with learning difficulties these stressors are compounded by the fact that their child is not meeting family and community expectations (LeMasters, 1970). The potential for failure related stress is especially high for parents of children with learning difficulties (Faerstein, 1981).

Positive parental attitudes have been found to have a significant positive effect on children's behavior. Rohner (1986) found that children raised in a warm, accepting, and nurturing environment exhibited more positive social skills. Cox (1970) found that the self-concept of a child was highly related to parental acceptance or rejection. Rohner, Chaille, and Rohner (1980) found that internal locus of control increased significantly with children's perceptions of increased parental acceptance. 
Children with learning difficulties have been found to view themselves more negatively than children without learning difficulties and their self esteem is negatively correlated with chronological age and years of schooling (Lefley, 1974; Luftig, 1983). Research suggests that this negative view of self is a selfperpetuating pattern, established early in the lives of children with learning difficulties, in which early failures lead to a lowered sense of competence, which, in turn, contributes to lowered expectations for future success, reduced achievement efforts and further failure (Adelman \& Taylor, 1983; Chapman, 1988; Chapman \& Boersma, 1979; and Rogers \& Saklofsky, 1985).

One way to impact the future mental health of children with learning difficulties is to implement early intervention programs which enhance the parent-child relationship. B. Guerney (1964) recognized this and developed filial therapy as an alternative method for treating young children with behavioral and emotional problems. Landreth (1991) expanded on this concept emphasizing that even parents whose children are not suffering from adjustment problems can benefit from learning how to relate more effectively to their children. Using a small group format, filial therapy is presented to parents through didactic instruction, viewing video tapes, and role-playing. The major therapeutic strategy is to train parents to become the therapeutic agent in their children's lives by teaching them to conduct special play sessions modeled after play therapy as practiced by Axline (1969), Ginott (1965), and Moustakas (1959). Unlike more behaviorally oriented therapies, this model of therapy is not directed 
toward specific problems, but is generic in nature. According to B. Guerney (1969) the filial play sessions have three main objectives: 1) allowing the child to more clearly understand the parent's feelings, attitudes, or behaviors toward him or her; 2) allowing the child to communicate thoughts, needs, and feelings to parents; 3) enhancing the child's self-respect, self-worth, and confidence.

Feelings such as frustration, anger, performance anxiety, separation anxiety, fear of abandonment, or concerns about personal safety which manifest in inappropriate and maladaptive behaviors can be addressed through encouraging the child to play them out in the safe, interpersonal atmosphere of a play session and in the presence of a warm, caring adult (Guerney, 1961). Once parents have completed the initial training period, they conduct regularly scheduled special play sessions in their home with their children while receiving supervision through the filial support group meetings.

Both the Guerneys' model (1966) and a shorter ten-week model developed by Landreth (1991) have been proven to be effective with a number of different populations. Filial therapy has been effectively used with parents of emotionally disturbed children (Sywulak, 1977/1978), parents of children with learning difficulties (Guerney, 1979), parents of children with stuttering problems (Andronico and Blake, 1971), parents of chronically ill children (GlazerWaldman, Zimmerman, Landreth, and Norton, 1992; Tew, 1997), children of divorced parents (Glazer-Waldman, 1991), single parents (Bratton, 1994), incarcerated fathers and their children (Lobaugh, 1992), incarcerated mothers 
and their children (Harris, 1995), and Chinese parents and their children (Chau, 1996; Yeun, 1997).

Children with learning difficulties face frustration not only in learning but also in relationships (Durrant, Cunningham \& Voelker, 1990). Filial therapy has been found to promote a more positive and secure relationship between parents and children (B. Guerney, 1964), to be effective in increasing the self-esteem level of parents (Glass, 1987), and to increase the acceptance level of parents toward their children (Bratton, 1994; Glass, 1987; Lebovitz, 1983; Lobaugh, 1992; Sensue, 1981; Sywulak, 1977). The dimension of parental acceptance has been shown to be linked to higher levels of self-esteem in children (Porter, 1954). Therefore filial therapy seems to be an appropriate choice for intervention and prevention with the families of children with learning difficulties.

\section{Statement of the Problem}

The problem with which this investigation was concerned was that of determining the effectiveness of filial therapy as a method of prevention and intervention for parents and children with learning difficulties. Specifically, this study was designed to determine the effectiveness of filial therapy in: a) increasing parental acceptance of children with a learning difficulty; b) reducing the stress level of parents of children with learning difficulties; c) decreasing social problems and total behavior problems of children with learning difficulties as reported by parents and teachers. 


\section{Synthesis of Related Literature}

The following review is a synthesis of theoretical constructs and research related to three major areas: (a) the variable of parental acceptance as it relates to the parent-child relationship and to the development of self-esteem in the child; (b) the use of filial therapy and its significance as an area of study; (c) the impact on the family when a child has a learning difficulty.

\section{Parental Acceptance}

Parental acceptance can be defined as the ability of parents to recognize and approve of their child regardless of appearance, abilities, or behavior. This unconditional parental acceptance is expressed when parents recognize that their child is a unique individual with feelings that need to be expressed and should be expressed. Parental acceptance entails the recognition of a child's need to differentiate from the parent and become an autonomous individual (Porter, 1954).

According to Coopersmith (1967) parental acceptance is expressed by a parent's sensitivity to a child's needs, desires, and interests, and a parent's unconditional love and approval of a child, without regard to the child's appearance, abilities, or performance. This expressed parental acceptance helps children learn that they can depend on significant others for support and help in life. With the freedom from anxiety that accompanies an accepting relationship with parents, children gain a certainty of their own worth and are 
able to express affection for others and work toward growth and maturity (Perkins, 1974).

Rogers (1951) stated that "a relationship of acceptance, as contrasted with positive or negative evaluation, reduces the need for defensiveness, and thus allows the child to dare to explore new ways of feeling and behaving ( $p$. 276). Research has shown that there is a correlation between parental acceptance and adjustment in children. Burchinal, Hawkes, and Gardner (1957) found that children who had fathers who were accepting scored lower on social maladjustment scales, and children whose mothers were accepting scored lower on a personal inferiority measure. Cox (1970) and Eisman (1981) asserted that parental acceptance or rejection is highly correlated to a child's self concept. Ausubel, Balthazar, Rosenthal, Blackman, Schpoont, \& Welkowitz (1954) found that children's perceptions of acceptance by parents are highly related to their perception of intrinsic valuation. One of the major conditions needed to develop children's self-esteem is parental acceptance (Cooper, Holman, \& Braithwaite, 1983; Coopersmith, 1967).

R. P. Rohner (1980) believes parental acceptance of children affects behavioral and personality dispositions in all facets of children's lives:

Parental acceptance or rejection predicts that rejected or emotionally abused children everywhere tend more than accepted children to be hostile and aggressive, or to have problems with the management of hostility and aggression; to be dependent or defensively independent, 
depending of the degree of rejection; to be emotionally unstable; to be emotionally unresponsive and to have a negative world view. (p. 5)

E. C. Rohner (1980) found that personality and behavioral dispositions of children varied directly with children's perception of parental acceptancerejection and that this relationship was not affected significantly by children's age or gender.

Locus of control in children has been shown to be related to parental acceptance. Rohner, Chaille, and Rohner (1980) found that children who perceived increased parental acceptance also experienced increases in their belief that they had control over events and actions in their lives, they experienced more of an internal locus of control.

\section{Filial Therapy}

The term "filial therapy" was first used by Bernard Guerney in the early 1960 s to describe an intervention aimed at helping parents utilize aspects of child-centered play therapy in the enhancement of their relationship with their own children. In filial therapy, parents are trained by therapists in the skills and strategies of child-centered play therapy as practiced by Axline (1969), Ginott (1965), and Moustakas (1959). Filial therapy enhances the relationship that already exists between a parent and child by facilitating the development of empathy, genuineness, and acceptance on the part of the parent. Parents develop and utilize these aspects of relationship with their children in weekly special play times. 
Filial therapy was originally conceived as an alternative therapeutic intervention for children who were experiencing behavioral and emotional difficulties. Landreth (1991) expanded the concept of relationship enhancement to all parents and children, stating that even children and parents who were not experiencing difficulties could benefit from leaning more effective ways of relating.

Filial therapy has been utilized and assessed for effectiveness in a number of different studies with different populations. Stover and B. Guerney (1967) examined the effects of training mothers in filial therapy techniques and found a significant increase in the use of reflective statements by the mothers and a decrease in directive statements, as measured by direct observation. Self-reports by the mothers indicated a positive influence on the parent-child relationship and the child's general emotional adjustment at the end of treatment.

Since the Stover and B. Guerney (1967) study did not utilize a control group, Oxman (1972) matched the parents in that study with volunteer parents on the variables of age of parents and children, size of family, geographical location and social economic status. Results showed that the mothers who had received filial therapy training in the Stover and B. Guerney (1967) study reported a significantly greater improvement in their children's behavior than did the matched control group.

B. Guerney and Stover (1971) substantiated their earlier 1967 findings 
with a group of 51 mothers and their children. They found that the mothers in both studies could learn to reflect feelings, allow their children self-direction, and demonstrate involvement in the emotional behaviors and expressions of their children. Assessments of psychosocial adjustment and symptomatology completed by clinicians and parents indicated improvement in all 51 children. Twenty eight of the children were rated as very much improved.

L. Guerney (1975) conducted a follow-up study of the participates in the B. Guerney and Stover (1971) study in order to examine the long term effects of filial therapy training. The original participants were surveyed one to three years later, the responses to the questionnaire indicated that only 1 of the 42 respondents needed to seek further treatment for the child. Thirty two of the respondents stated that their children had continued to improve, with 64 percent of the parents stating that the children's continued improvement was related to their improved ability to relate to the children. The parents' overall evaluation of the filial therapy training was positive. This follow-up study suggests that the positive results of the filial training may still be in effect as long as three years later.

In order to avoid the potential differences between parents who seek treatment and those who do not, Sywulak (1977) utilized a design in which the participants served as their own control group. The study presented process data as well as pre and post data in that the participants, 13 mother/father pairs and 6 single mothers, were asked to complete assessment instruments four 
months prior to training, at a two-month midpoint during training, and finally after four months of training. The results of the study showed significant improvement in child adjustment as well as in parental acceptance. The improvements were evident at the two-month midpoint and maintained after four months of training.

Sensue (1981) conducted a three-year follow-up study of the participants in the Sywulak (1977) study and found scores that were higher at the end of sixmonths of treatment and no significant losses two to three years later. A comparison group of parents matched for age, gender, socioeconomic status, and education level whose children were considered to have age typical behavior were found to show no significant differences from the children who had been formerly diagnosed as maladjusted and had undergone the filial therapy training. Both the parents and the children who had filial training asserted that the filial training had resulted in positive change within the family.

Wall (1979) examined three variations of play therapy conducted by: (a) graduate therapist trainees; (b) non-trained parents; and (c) parents directed and observed by therapist trainees. Parents who interacted with therapist trainees improved their skills in empathic communication with their children. The children's expression of negative feelings and their increased ability to accurately perceive negative attitudes in their families demonstrated their improved adjustment. Wall (1979) concluded that the parent's acceptance of negative feelings might have a more powerful effect on children than acceptance of the same feelings by a therapist. 
Payton (1980) conducted a study in which parents and paraprofessionals who received filial therapy training were compared to a control group. Parents trained in filial therapy showed significantly higher scores on parenting attitude than either the paraprofessional or the control group. Parents trained in filial therapy also reported significant improvement in their children's behaviors as compared to either the paraprofessional or the control group. Payton (1980) concluded that parents trained in filial therapy were more effective than paraprofessionals in impacting their children's personality adjustment.

Lebovitz (1983) compared the effectiveness of a filial therapy group, a group conducting supervised play sessions, and a group receiving no treatment. Mothers' filial therapy skills were measured and change was assessed by parents, teachers, and independent observers. In both filial therapy and play session group programs, children demonstrated proportionately fewer problem behaviors than did the control group. The filial therapy group exhibited a greater decrease in problem behaviors than did the play session group. The filial therapy group mothers communicated more acceptance of their children's feelings, allowed their children more self-direction, and demonstrated more involvement with their children than did mothers in the play session group. Children in the filial therapy group evidenced a greater decrease in dependence than did the children in the play session group. Parents in both the filial therapy group and the play session group reported that they became more accepting of their children. These finding were not demonstrated in the control group. 
Kezur (1980) studied children who received play therapy sessions with their parents in addition to sessions with a therapist. The nature of mother-child communication and the effects of these communication patterns on the relationship were examined. The mothers in the study received parent training while their children were seen in individual play therapy by a trained therapist. The mother and child then met jointly in play sessions which were video taped for the purpose of feedback from the therapist. The following results were obtained: (a) effective communication skills, based on therapeutic principles, were developed by the mothers; (b) the children who expressed anger towards their mothers in the therapist facilitated play sessions became more open and communicative with their mothers in the parent play sessions;(c) new awarenesses in communication were developed by mothers; (d) mothers who grew in self awareness changed in positive directions with their children; (e) mothers were better able to meet the needs of their children when they learned to honor their own needs; (f) new communication skills were developed by mothers who accepted joint responsibility for the problems with their children; (g) greater gains in communication skills were made by mothers who opened themselves to a relationship with the researcher; (h) positive changes developed in the mother-child relationship as both gained in self-esteem; (I) mothers gained more from feedback when they were open to viewing and commenting on themselves in videotape review; (j) closeness and effective communication increased as mothers and children became more involved in the joint sessions; 
(k) in the mother-child pairs where the most change occurred, the mothers tended to report improvement in other relationships.

Dematatis (1981) compared traditional filial therapy training with an integrated filial therapy training program which included affect simulation and videotape recall modeled after Kagan's Interpersonal Process Recall (IPR) training. Significant gains in parental acceptance, affect sensitivity, allowance of self-direction and involvement were found in both groups.

Glass (1987) compared the effectiveness of the Landreth (1991) 10-week filial therapy training model with a control group of parents who received no training. The parents in the filial therapy group significantly increased in feelings of unconditional love for their children and significantly decreased their perception of expressed conflict in their family. Further results, though not statically significant, indicated positive directional trends in that filial therapy produced positive changes in parental acceptance, respect for children's feelings and their right to express themselves, recognition of children's need for autonomy and independence, self-esteem of parents and children, closeness between parent and child, and family environment.

Findings in a case study conducted by Packer (1990) showed that after filial training parents perceived themselves as possessing skills which could effect positive changes in the behavior of their children. Gains documented for the child during filial therapy were reduced temper tantrums and an increased ability to control escalation of rising emotions in both the home and child care 
environments. The father was more readily accepted as an authority figure in the presence of the mother as a result of the filial therapy.

Filial therapy has been used with a number of special populations and in a variety of settings. Hornsby and Applebaum (1978) examined a series of 60 clinical cases and reported that filial therapy had been effective with children with a variety of diagnoses. Filial therapy was reported to be effective with a borderline psychotic child, a child in active conflict with a parent, and a handicapped child. Improvement in parent-child relationships and the children's problem behaviors were evidenced. The parents stated that they liked filial therapy because they were involved in the psychotherapeutic process.

When filial therapy was applied in the school setting, it was shown that involving parents in their children's treatment ameliorated the parents blaming of the school for their child's problems because they no longer felt helpless. Parents involved in filial therapy were also found to be more motivated to undertake and stay with their children's treatment (Andronico \& B. Guerney, 1967; Ellinwood, 1989; B. Guerney \& Flumen, 1970).

Andronico and Blake (1971) examined the effects of filial therapy on young children with stuttering problems and reported that parents became more involved in their children's treatment, developed positive parent-child interactions, and effectively changed the home environment. Results indicated that parents learned to inhibit their tendency to cut off or pressure the child who was stuttering, and that the learning was generalized into the parents' day-to- 
day interactions with the child.

Boll (1972) studied the effects of filial therapy with mothers of mentally retarded children comparing a traditionally trained filial therapy group of mothers, a group trained in filial therapy and given information on specific reinforcement and extinction techniques, and a control group. Results indicated that both groups trained in filial therapy perceived improvement in the socially adaptive behavior displayed by their children, with the highest improvement being noted in the traditionally trained group. Boll (1972) conjectured that this difference might be accounted for by the fact that parents in the traditionally trained group seemed to form a closer relationship with each other and that their attendance was better than the parents in the group where there was an expert who taught information on reinforcement and extinction techniques.

B. Guerney (1976) examined the effectiveness of filial therapy as a treatment for emotionally disturbed children and found that the children showed significant improvement on the measures of social adjustment and reduction in conflicts with parents, teachers, and peers. The mothers' dissatisfaction with their children and the number of children's symptoms decreased significantly. The results held true across the range of the sample regardless of socioeconomic background, degree or kind of child maladjustment, maternal attitude, or personality variables.

Ginsberg (1976) researched the effectiveness of filial therapy in a community mental health center. Foster parents, single parent families, and 
families with different socioeconomic status were trained in filial therapy and positive results were found across all groups. Significant changes were found on parent reports, school progress, and sibling and peer interaction for mothers living in a low socioeconomic community. Filial therapy was found to reduce stress and enhance the ability of foster or adopted children and parents to build a mutually satisfactory relationship. L. Guerney and Gavigan (1981) found similar results in that foster parents showed more acceptance of their foster children after filial therapy training.

L. Guerney (1979) used filial therapy training with the parents of children who were described as having adjustment difficulties that were secondary to what she described as disorders that were essentially physical in origin, such as learning disabilities, hyperactivity syndrome, physical disabilities, and mild retardation. The children in the study were able to utilize the play sessions as fully as other children in past studies. During filial therapy they moved from negative feelings about themselves and others to positive feelings, from dependence toward independence, and from a lack of impulse control to self control that was comparable to children who were not labeled as dysfunctional.

Glazer-Waldman (1991) studied the effectiveness of the Landreth (1991) 10-week filial therapy model with the parents of chronically ill children and found that there was not a statistically significant difference between pre-test and posttest measures of acceptance and anxiety for parents of chronically ill children. However, the five parents in the study did report positive change in themselves 
and positive change in their children. A comparison of the scores on the measures of anxiety found that the filial group parents' perceptions of their children's anxiety was more closely matched to the children's actual anxiety scores on the post-test.

Lobaugh (1992) studied the effectiveness of the Landreth 10-week filial therapy model with incarcerated fathers. When compared to the control group the fathers in the filial group significantly increased their acceptance of their children and significantly reduced their level of parental stress. The self-esteem of the children involved in filial therapy with their fathers significantly increased and their problematic behaviors, as perceived by the parent, decreased significantly.

Utilizing ethnographic methodology, Lahti (1993) examined the Landreth (1991) 10-week filial therapy training process and effects on the parent, child, and the parent-child relationship. The finding revealed that the essential nature of the training process focused on balancing a didactic component with a group counseling format in order to provide an atmosphere conducive to personal exploration and support along with teaching parenting skills. The play sessions were facilitating to change in that they allowed the parents to be the agents of change for a short period of time. The parents stress while learning also appeared to be lessened as a result of the sessions. Parents reported gaining a sense of objectivity through reviewing video-taped sessions and the process of receiving and giving feedback with the group. Parents reported changes 
including increased confidence and feelings of personal power, reduction in the degree of parental control and responsibility, and increased awareness of personal as well as children's needs. Increased and enhanced communication, more realistic expectations, and less friction were reported as contributing to closer parent-child and martial relationships. Changes in children included increased and enhanced communication, increased responsibility for actions, decreased withdrawn and aggressive behavior, and increased feelings of happiness.

Using a phenomonological approach, Bavin-Hoffman (1994) conducted a three year follow-up study using a phenomenological approach of 20 married couples who had participated in the Landreth (1991) 10-week filial therapy training model. Recurring themes of improved communication and behavior where revealed. Parents reported increased unity, understanding of their children's play, parental confidence, and acceptance of their children.

In a control group study of the effectiveness of the Landreth 10-week filial therapy training model with single parents, Bratton (1994) found that filial therapy training equipped single parents with healthier parenting skills and provided them with the emotional support they needed. Significant increases in single parents' empathy toward their children, acceptance of their children, ability to allow self-direction, and involvement with their children were obtained as a result of filial therapy. Single parents increased significantly in respect for their children's feelings, their children's unique make-up, their children's need for 
autonomy, and need for unconditional love. Overall parental stress decreased significantly as well as perceived problems of child behavior.

Harris (1995) studied the effectiveness of the Landreth (1991) filial therapy model with incarcerated mothers by condensing the model into five weeks. Twelve incarcerated mothers received two hour filial therapy training sessions biweekly for five weeks and conducted biweekly 30-minute play sessions with one of their children. Compared with mothers in the control group, the mothers in the experimental group significantly increased their empathic interaction with their children, attitude of acceptance toward their children, and decreased the number of reported problems with their children's behavior.

Chau (1996) investigated the effectiveness of the Landreth (1991) filial therapy model with Chinese parents. After a 10-week filial therapy training program, the Chinese parents who received training had significant changes over the Chinese parents in the control group who did not receive training. The parents trained in filial therapy evidenced a significant increase in their level of empathic interactions with their children, a significant increase in their attitude of acceptance toward their children, and a significant reduction in their level of stress related to parenting.

Glover (1996) investigated the effectiveness of the Landreth (1991) 10week filial therapy training model as an intervention for Native American parents and their children residing on the Flathead Reservation in Montana. Children who participated in filial therapy play sessions with their parents significantly 
increased their level of desirable play behaviors with their parents. Although the measures of parental acceptance, parental stress, and children's self-concepts did not show significant change, there were positive trends on all measures. This study gives rise to questions regarding the suitability of current self concept measurement instruments for Native American children and possible cultural differences in the concepts of parental stress and parental acceptance.

Tew (1997) studied the efficacy of filial therapy with families of chronically ill children using the Landreth (1991) 10-week filial therapy model. These families of chronically ill children showed significant declines in stress after participating in the 10 -week filial training. The parents trained in filial therapy made significant positive gains in their perceived acceptance of their children. The parents reported fewer problematic behaviors in their children after training as well as less anxious/depressed behaviors.

Yeun (1997) investigated the effectiveness of the Landreth 10-week filial therapy training model with immigrant Chinese parents in Canada. The parents who received training evidenced a significant increase in their level of empathic interaction with their children, a significant increase in their acceptance level toward their children, a significant decrease in their level of stress related to parenting, and a significant decrease in the number of problem behaviors they perceived in their children.

Parenting Children with Learning Difficulties

The ability of a child with learning difficulties to cope with those difficulties 
is influenced by the severity of the difficulty, the supportiveness of the environment, the child's self-concept, and previous experience with confronting failure (Latson, 1986). For the parents of a child with learning difficulties, the more marginal the difficulty, the more difficult the task becomes of successfully completing the work of grief for the parent. Inconsistency in parenting may be one manifestation of the grief parents experience. This reaction is initiated by uncertainty in the parent and lack of response from the child, and maintained by feelings of helplessness (Wikler, 1981).

Families with children who have a learning difficulty have been found to be more chaotic and less stable than families whose children do not exhibit these difficulties. Communication was found to be unclear, rules were not clearly defined, and marital breakup was common in these families (Amerikaner \& Omizo, 1984). Ditton, Green, and Singer (1987) found that families with a child who has learning difficulties exhibit more communication deviances such as commitment or referent problems which leave listeners confused concerning intended meaning. Owen, Adams, Forrest, Stolz, and Fisher (1971) found that families with a child who has learning difficulties were rated significantly more disorganized and unstable than the families in nondisabled control groups.

Feagans, Merriwether, \& Haldane (1991) studied goodness of fit (the family's acceptance of the child) in families with children who experienced learning difficulties. They concluded that children from homes with high ratings on goodness of fit, regardless of learning difficulties, performed better than their 
low-fit subgroups on achievement measures during elementary school. The child's fit in the family, the family's acceptance of the child, was more important to achievement than was the presence or lack of a learning difficulty.

Tollison, Palmer, and Stowe (1987) proposed that lower expectations, as related to their children's achievement, of mothers of children with learning difficulties reflected sensitivity to, and possible acceptance of, their children's needs. Morvitz \& Motta (1992) found that maternal self-esteem was not as significant to a child's self-esteem as was the mother's ability to convey acceptance to the child in a way that the child could perceive her acceptance. O'Hara and Levy (1984) pointed to parental grief in families of children with learning differences as a factor in parents not accepting their children.

\section{Summary}

Families with children who have learning difficulties have been found to be more chaotic and less stable than families whose children do not exhibit these difficulties (Amerikaner \& Omizo, 1984). Because chaotic and unstable families are at risk for less than optimal parenting early intervention and prevention strategies are needed. Healthy child-parent relationships facilitate optimal parenting and filial therapy has been proven to encourage such healthy relationships (Bratton, 1994; Chau, 1996; Harris, 1995; Lobaugh, 1992; Tew, 1997; Yeun, 1997).

Parental attitudes have been linked with child attitudes and behaviors in numerous studies. Rohner (1986) found that children raised in a warm, 
accepting, and nurturing environment exhibited more positive social skills.

Children's internal locus of control has been found to increase significantly with when their perceptions of parental acceptance increase (Rohner, Chaille, and Rohner, 1980). Cox (1970) found that the self-concept of children were highly related to parental acceptance or rejection.

Children experiencing learning difficulties must cope with those difficulties, the supportiveness of their parents significantly effect their ability to do so (Latson, 1986). Research indicates that parents of children with learning difficulties perceive their children as having behavioral characteristics that make their parenting role more difficult. Filial therapy offers parents training in skills that help ease the stress associated with parenting and promote acceptance of both the child and self. 


\section{CHAPTER $\|$}

\section{METHODS AND PROCEDURES}

The purpose of this study was to determine if filial therapy is effective in: 1) increasing the acceptance level of parents who's child is experiencing a learning difficulty; 2) reducing the stress level of those parents of children with learning difficulties; 3 ) decreasing social problems and total behavior problems as reported by both parents and teachers. This chapter will address definition of terms, hypotheses, instrumentation, selection of subjects, collection of data, the ten-week training model, the facilitator, and statistical analysis.

\section{Definition of Terms}

Filial therapy was defined in this study as "a unique approach used by play therapists to train parents to be therapeutic agents with their own children through a format of didactic instruction, demonstration play sessions, required at-home laboratory play sessions, and supervision. Parents are taught basic child-centered play therapy skills including responsive listening, recognizing children's emotional needs, therapeutic limit setting, building children's self esteem, and structuring required weekly play sessions with their children using a special kit of selected toys. Parents learn how to create a nonjudgmental, understanding, and accepting environment which enhances the parent-child 
relationship, thus facilitating personal growth and change for child and parent" (G. L. Landreth, personal communication, June 27, 1995).

Play Therapy is defined by Landreth (1991) as " a dynamic interpersonal relationship between a child and a therapist trained in play therapy procedures who provides selected play materials and facilitates the development of a safe relationship for the child to fully express and explore self (feelings, thoughts, experiences, and behaviors) through the child's natural medium of communication, play" (p. 14).

Parent and/or. Parenting includes any significant care giver, not necessarily biological or adoptive parent, and the functions performed by such a care giver.

Child with a learning difficulty was defined in this study as a child between the ages of 3 years and 10 years who has been identified by parent or school personnel as exhibiting a learning difficulty or to be at-risk for learning difficulties.

Parental acceptance includes the feelings and behaviors on the part of the parents which are characterized by unconditional love for the child, a recognition of the child as a person with feelings who has a right and a need to express those feelings, a value for the unique make-up of the child, and a recognition of the child's need to differentiate and separate from the child's parents in order to become an autonomous individual (Porter, 1954). For the purpose of this study, parental acceptance was operationally defined as the 
parents' scores on the Porter Parental Acceptance Scale (PPAS)(Porter, 1954).

Respect for the child's feelings and right to express them, denotes the parents' willingness to allow the child to express feelings and still show positive regard for the child. For the purpose of this study, respect for the child's feelings and right to express them was operationally defined as the parents' scores on this subscale of the PPAS (Porter, 1954).

Appreciation for the child's unique make-up means that a parent values and shows pleasure in the child's uniqueness. For the purpose of this study, appreciation of the child's unique make-up was operationally defined as the parents' scores on this subscale of the PPAS (Porter, 1954).

Recognition for the child's need for autonomy and independence denotes the parents' understanding of children's need to differentiate and separate from their parents in order to mature in a healthy manner. For the purpose of this study, recognition for the child's need for autonomy and independence was operationally defined as the parents' scores on this subscale of the PPAS (Porter, 1954).

Unconditional love is the love a parent shows toward a child without placing conditions or minimum standards on the child's behavior in order to receive that love. For the purpose of this study, unconditional love was operationally defined as the parents' scores on this subscale of the PPAS (Porter, 1954).

Parental stress describes the degree of stress in the parent-child system 
as perceived by the parent. For the purpose of this study, parental stress was operationally defined as the parents' scores on the Parenting Stress Index (Abidin, 1983).

Externalizing behavior problems refers to aggressive behavior such as excessive arguing, meanness to others, and temper tantrums. Externalizing behavior problems also refer to delinquent behavior such as not displaying guilt after misbehavior, lying, cheating, and stealing (Achenbach, 1991). For the purposes of this study, Externalizing Behavior Problems was operationally defined as the score on the Externalizing subscale of the Child Behavior Checklist.

Internalizing behavior problems refers to withdrawn behavior such as preferring to be alone, refusing to talk, and being secretive. Internalizing behaviors problems also refer to anxious/depressed behaviors such as complaining of loneliness, excessive crying, and perfectionism. Somatic complaints such as being overly tired, and physical problems without any known medical cause such as headaches and nausea are also included in internalizing behavior problems (Achenbach, 1991). For the purposes of this study, Internalizing Behavior Problems was operationally defined as the score on the Internalizing subscale of the $\mathrm{CBCL}$.

Hypotheses

To carry out the purposes of this study, the following hypotheses were formulated: 
1) The experimental group parents will attain a significantly higher mean total score on the Porter Parental Acceptance Scale (PPAS) post-test than will the control group parents.

1a) The experimental group parents will attain a significantly higher mean score on the "Respect for the Child's Feelings and Right to Express Them" subscale of the PPAS post-test than will the control group parents.

1b) The experimental group parents will attain a significantly higher mean score on the "Appreciation of the Child's Unique Makeup" subscale of the PPAS post-test than will the control group parents.

1c) The experimental group parents will attain a significantly higher mean score on the "Recognition of the Child's Need for Autonomy and Independence" subscale of the PPAS post-test than will the control group parents.

1d) The experimental group parents will attain a significantly higher mean score on the "Unconditional Love" subscale of the PPAS post-test than will the control group parents.

2) The experimental group parents will attain a significantly lower mean total score on the Parenting Stress Index (PSI) post-test than will the control group parents.

2a) The experimental group parents will attain a significantly lower mean score on the "Parent Domain" of the PSI post-test than will the control group parents.

2b) The experimental group parents will attain a significantly lower mean 
score on the "Child Domain" of the PSI post-test than will the control group parents.

3) The experimental group children will attain a significantly lower mean score on Externalizing Behavior Problems as indicated on the Parent Report Form of the Child Behavior Checklist (Achenbach \& Edelbrock, 1981, 1983) at post-testing than will the control group children.

4) The experimental group children will attain a significantly lower mean score on Internalizing Behavior Problems as indicated on the Parent Report Form of the Child Behavior Checklist (Achenbach \& Edelbrock, 1981, 1983) at post-testing than will the control group children.

5) The experimental group children will attain a significantly lower mean score on Total Behavior Problems as indicated on the Parent Form of the Child Behavior Checklist ( Achenbach \& Edelbrock, 1981, 1983) at post-testing than will the control group children.

6) The experimental group children will attain a significantly lower mean score on Externalizing Behavior Problems as indicated on the Teacher Report form of the Child Behavior Checklist (Achenbach \& Edelbrock, 1986; Edelbrock \& Achenbach, 1984) at post-testing than will the control group children.

7) The experimental group children will attain a significantly lower mean score on Internalizing Behavior Problems as indicated on the Teacher Report form of the Child Behavior Checklist (Achenbach \& Edelbrock, 1986; Edelbrock \& Achenbach, 1984) at post-testing than will the control group children. 
8) The experimental group children will attain a significantly lower mean score on Total Behavior Problems as indicated on the Teacher Report form of the Child Behavior Checklist (Achenbach \& Edelbrock, 1986; Edelbrock \& Achenbach, 1984) at post-testing than will the control group children.

Instrumentation

\section{Porter Parental Acceptance Scale}

The Porter Parental Acceptance Scale (PPAS) was developed by Porter (1954). The PPAS is a self-report inventory designed to measure parental acceptance as revealed in the parents behavior and feelings toward, about, or with their child. Variables measured by the instrument are: 1) respect for the child's feelings and right to express them, 2) appreciation of the child's unique make-up, 3) recognition of the child's need for autonomy and independence, and 4) unconditional love.

The instrument consists of 40 items, each with five multiple choice responses ranging from a low level of acceptance to high level of acceptance. Two dimensions of acceptance are incorporated into the scale. The first reveals how the parent feels in a specific situation. The second reveals the parents' manifested behavior in a specific situation. The test may be scored to yield four subscale scores and one total score. Higher scores indicate higher levels of positive behavior in the total score and in each of the subscales.

Porter (1954) reported a split-half reliability correlation of .766 raised by the Spearman Brown Prophecy formula to .865. Later research reported a split- 
half reliability coefficient of .666 raised by the Spearman Brown formula to a total test reliability of .800 . Both reported coefficients are significant beyond the .01 level (Burchinal, Hawkes, \& Gardner, 1957).

Porter (1954) investigated the validity of the Porter Parental Acceptance Scale instrument through utilizing five expert judges to rank the possible responses on a continuum of one representing low parental acceptance to five representing high parental acceptance. On all items there was agreement among at least three out of the five judges. The greatest degree of disagreement was by a distance of only two scale points which occurred in less than 20 percent of the responses suggesting that the operational definition of parental acceptance that Porter (1954) created is valid as measured by this scale.

Internal consistency of the scale was investigated by Burchinal et al. (1957) using item analysis. All items discriminated between high and low scoring fathers with the exception of one item which failed to show significance. Analysis of mothers' responses yielded similar results. In fact 35 items in the mothers' responses and 33 in the fathers' responses were significant at the .001 level of probability clearly demonstrating that the items discriminated consistently between high and low scorers. The instrument was thus deemed to be internally consistent.

\section{Parenting Stress Index}

The Parenting Stress Index (PSI) was developed by Abidin (1983). This 
self-report inventory is a 101 item index designed to measure the level of stress in the parent-child system. The items are separated into two domains, the parent domain and the child domain. The parent characteristics measured by the PSI include parent's sense of competence, parent attachment, restriction imposed by the parental role, parent's feelings of social isolation, parent depression, relationship with spouse, and parental health. The child characteristics measured include the child's acceptability to the parent, the child's level of demandingness, the child's moodiness, the child's degree of distractibility, the child's adaptability, and the child's reinforcement of the parent. Higher scores indicate higher levels of stress and perceived negative behavior in the total score and in each of the subscales.

Zakreski (1983) used the test-retest method to determine a coefficient of reliability. This study produced coefficients of .778 for the child domain, .69 for the parent domain, and .88 for the total index. Alpha reliability coefficients were calculated on each total score and on each of the domains to determine internal consistency. The coefficient reported for the child domain was .89 and the coefficient for the parent domain was .93 with a total reliability coefficient of .95 . These finding indicate a high degree of internal consistency for the PSI (Hauenstein, Scarr, \& Abidin, 1987). Parent Report Form of the Child Behavior Checklist

The Child Behavior Checklist Parent Report Form ( $\mathrm{CBCL}$ ) was developed by Achenbach \& Edelbrock $(1981,1983)$. In the current study, the 1991 profile 
(Achenbach, 1991) will be used. The $\mathrm{CBCL}$ is a 113 item scale used with children from two to sixteen years of age. The form is designed to be filled out by the parent and takes approximately 20 minutes to complete. The Behavior Problem Scale consists of 113 items that have been factor analyzed into nine subscales (Achenbach, 1991): Withdrawn, Somatic Complaints, Anxious/Depressed, Social Problems, Thought Problems, Attention Problems, Delinquent Behaviors, Aggressive Behaviors, and Sex Problems. A secondorder factor analysis of the Behavior Problem Scale yielded two primary factors labeled Internalizing and Externalizing. A total Behavior Problem Scale may be computed. The scores for each subscale and factor can be computed, resulting in T-scores and percentiles.

Internal consistency is built in because the syndrome scales are derived from principle components of the correlation among items. For girls age 4-11, Cronbach's alpha is .90 for Internalizing Behavior Problems and .93 for Externalizing Behavior Problems. For boys age 4-11, Cronbach's alpha is .89 for Internalizing and .93 for Externalizing Behavior Problems. Cronbach's alpha represents the mean of the correlations between all possible sets of half the items comprising a scale. Inter-interviewer reliability of item scores was established at .959 for the problem items by comparing scores arrived at by three interviewers with 241 matched triads of children.

Test-retest reliability was established at .89 for Internalizing Behavior Problems and at .93 for Externalizing Behavior Problems. Long-term stability 
(two years) of scaled scores was established at .70 and .86 for Internalizing and Externalizing Behavior Problems respectively. Children who were receiving mental health services obtained long-term stability coefficients that were generally lower with significant decreases in problem scores, indicating the CBCL is sensitive to the effects of interventions with children.

Content validity is supported by the $\mathrm{CBCL}$ items being able to discriminate significantly between demographically matched referred and nonreferred children. Construct validity is supported by significant association with analogous scales on the Conners Parent Questionnaire (1973) and the QuayPeterson Revised Behavior Problem Checklist (1983). Criterion-related validity is supported by the ability of the CBCL's quantitative scale scores to discriminate significantly between demographically matched referred and non-referred children.

\section{The Child Behavior Checklist Teacher Report Form}

The Child Behavior Checklist Teacher Report Form (CBCL-Teacher Report) (Edelbrock \& Achenbach, 1984; Achenbach \& Edelbrock, 1986) is modeled after the parent report, with appropriate changes to reflect school related behaviors. The teacher's report form has 93 of the same behavioral/emotional items as the $\mathrm{CBCL}$, some of which have slight modifications such as the substitution of "pupils" for "children". Twenty five items on the $\mathrm{CBCL}-T$ eacher Report are different than the CBCL items and reflect aspects that are more pertinent to teachers. The scales for the CBCL-Teacher 
Report were derived from factor analyses of $\mathrm{CBCL}-T e a c h e r$ Report forms completed for 1700 children referred for mental health or special school services. The Behavior Problem Scale has been factor analyzed into eight subscales: Withdrawn, Somatic Complaints, Anxious/Depressed, Social Problems, Thought Problems, Attention Problems, Delinquent Behaviors, and Aggressive Behaviors (Achenbach \& Edelbrock, 1986). Second-order factor analyses produced two broad-band groupings; Internalizing and Externalizing. A total problem behavior scale may also be computed. Computing scores for each of the subscales and factors will yield T-scores and percentiles.

\section{The Teacher Report Form of the Child Behavior Checklist has been} shown to correlate highly with various scales of the revised Conners Teacher Rating Scale that assesses externalizing behavior problems (Edelbrock, Greenbaum, \& Conover, 1985). The instrument has also been shown to discriminate between clinic-referred and nonreffered children (Edelbrock \& Achenbach, 1984).

\section{Selection of Participants}

Fliers announcing the beginning of "parent-child relationship enhancement classes for the parents of children with learning difficulties" were sent home with children from two participating school systems in the north Texas area. Fliers were also posted in the participating school buildings. Parents who responded by the advertised deadline were contacted by the researcher and given more details about the parent training classes and the selection process. 
The classes were offered free of charge.

Forty-one parents were selected to participate in the study based on the following criteria: (a) must be the primary care giver of a child between the ages of 3 years and 10 years who is not currently in therapy and has been identified as having a learning difficulty; (b) must be able to speak, read, and write the English language; (c) must be able to attend the ten weeks of filial therapy training; (d) must agree to participate in weekly 30-minute home play sessions with their child; (e) must be willing to sign the consent to participate form; and, (f) must not be currently enrolled in parent training classes.

The investigator spoke with each parent participant who met the specified criteria to explain the purpose and the requirements of the filial therapy training, provide information about how confidentiality would be maintained, and answer any questions the participants had before they signed the consent form (Appendix A). Each parent was asked to select only one child, between the ages of 3-10 years, who they had identified as having a learning difficulty as the "child of focus" for the ten week training period. Convenience sampling based on parent availability to attend specified group meeting times, leaving all other factors random, was used in the assignment of parents to the experimental group. All other parents being assigned to the wait list control group which was offered training upon completion of the first series of filial training classes.

Nineteen volunteers were placed in the experimental group and 22 volunteers in the control group. The 19 experimental group parents who met the 
criteria specified were scheduled to attend the group location and time for which they were available in order to complete all pretest requirements. Of the 22 parents initially placed in the control group 15 completed the pretest assessment packets. The seven parents who did not complete the pretest requirements were contacted by the researcher, each stated they would return the packet but did not do so. Of those 15 control group parents who returned the pretest assessment packets 11 completed the post-test assessment instruments. Of the 19 parents initially placed in the experimental group 15 completed the pretest battery of assessment instruments. The four experimental group parents who did not complete the pretest requirements stated they could not do so due to a lack of time. Of the 15 experimental group parents who completed the pretest packets, two were unable to complete the training due to job transfers out-ofstate and two additional parents were unable to complete the training due to family problems. Consequently 22 participants completed the present study, 11 in the control group and 11 in the experimental group.

In the experimental phase, two filial therapy training groups were offered in two north Texas elementary school settings. Parents were assigned to one of the two groups according to (a) work and school schedule and (b) the elementary school in their area. Group A $(n=6)$ met on Monday nights, and Group $B(n=5)$ met on Thursday nights. Each group met weekly for a two hour training session for 10 consecutive weeks in the elementary school their child attended. 
There was no discrimination on the basis of gender, age, ethnicity, or religion. The experimental group was comprised of seven mothers, three fathers, and one grandmother. The control group was comprised of 10 mothers and one grandmother. The households of the experimental group were comprised of eight married natural parents, one blended family, one single mother, and one grandmother. The households of the control group were comprised of seven married natural parents, one blended family, two single mothers, and one grandmother. The age range for the experimental group was from 30 to 63 years of age, with a mean age of 43 . The parents in the control group ranged in age from 27 to 49 , with a mean age of 37 . The experimental group was comprised of $82 \%$ caucasian and $18 \%$ bi-racial. The control group was comprised of $63 \%$ caucasian, $27 \%$ bi-racial and $10 \%$ native American. Of the experimental group parents, $82 \%$ had completed high school and $18 \%$ had completed college. Of the control group parents, $9 \%$ had not completed high school, $73 \%$ had completed high school, $9 \%$ had completed college and $9 \%$ had completed a postgraduate degree.

Although all the children in the experimental and control groups had been identified by their parents as having learning difficulties, in the experimental group $9 \%$ had been formally diagnosed with Anxiety Disorder, $18 \%$ had been formally diagnosed with Attention Deficit Hyperactivity Disorder (ADHD) and were receiving medication, and $9 \%$ had been formally diagnosed with a Learning Disability. In the control group, $36 \%$ had been diagnosed with ADHD and were 
receiving medication and $27 \%$ had been diagnosed with a Learning Disability.

The parents in the experimental and control groups were similar in levels of education and household makeup. The experimental group included male participants which was not matched in the control group. The experimental group participants were older and slightly less culturally diverse than control group members. Fewer of the children of the experimental group parents had been formally diagnosed.

\section{Collection of Data}

During the first training session for each filial therapy group parents completed the (a) Porter Parental Acceptance Scale (Appendix C); (b) Parenting Stress Index; (c) Child Behavior Checklist; and (d) a Child Data Sheet . The teacher of each child of focus completed the Child Behavior ChecklistTeacher Report. Child care was provided for the children while their parents participated in the filial training sessions. The researcher was available to answer any questions the parents might have regarding the battery of instruments. Parents were reminded to respond to all items in terms of their interaction with their child of focus. The control group parents who were unavailable to attend the specified group meeting times were mailed assessment packets identical to the experimental group packets and asked to complete and return via mail to the investigator in an enclosed pre-addressed, postage paid envelope. The researcher enclosed her phone number with a statement of her availability to answer any questions regarding the battery of instruments. 
During the last week of the 10-week filial therapy training sessions, the post-test battery of instruments was administered to parents in the experimental group. The post-test battery of instruments was mailed to the control group subjects based on the return date of their pre-test battery of instruments to ensure a 10-week interval. The post-training session followed the same procedures outlined in the pre-training session. The control group parents were given the opportunity to participate in free of charge filial therapy training following completion of the post-testing requirements.

The information provided on questionnaires was kept confidential. Information obtained from the questionnaires was recorded with a code number. Only the researcher had the list of the participants' names. At the conclusion of this study, the list of participants' names was destroyed.

\section{Ten-Week Training Model}

The experimental group parents' schedules necessitated a slight modification in the Landreth (1991) 10-week training model. Three-fourths of the time in sessions one and ten was used for testing. Instead of a full two hours of training, parents received only 30 minutes of training in each of these sessions. Sessions two through nine were two hours in length each week (See Appendix D). Each group met in the elementary school library of the local school which their child attended. Child care was provided on site.

The Landreth (1991)10-Week Filial Therapy Training Model utilizes both didactic and dynamic components and was designed to enhance the parent- 
child relationship by helping parents learn how to create an accepting

environment in which their children will feel safe enough to express and explore thoughts and feelings. In order to facilitate the parents being able to provide this type of environment they were taught reflective listening skills and therapeutic limit setting. Parents were also instructed not to criticize behavior, not to praise, not to offer information or teach, and not to initiate new activities. The parents were taught these new skills through demonstration and role play and were then required to practice with their "child of focus" in weekly 30 -minute special play sessions. They then shared their experiences with the training group. The parents were supplied with a special toy kit (described in the filial therapy handouts in Appendix D). In addition, each participant was video-taped once during the 10-week training. All parents had access to a video camera, and video-taped themselves at home. Each parents' tape was reviewed during a group session and the participants received feedback as well as the opportunity to observe other parents during their special play times. The training sessions followed the methodology outlined by Landreth (1991) for a 10-week filial therapy training group (session outlines and handouts are included in Appendix D).

\section{Training Session One}

During session one, parents were asked to introduce themselves, describe their families, and characterize their "child of focus". Goals and objectives of the training were explained. Then, informed consent forms were 
given to parents and signed. Upon getting informed consent, parents were given the following instruments to complete: the Child Behavior Checklist, the Parenting Stress Index, the Porter Parental Acceptance Scale, and a child data/demographics sheet. Parents were introduced to the importance of emotions through a video segment from "Children's Emotions." The facilitator described the skills of reflective listening and tracking behavior and illustrated these skills through role play with one of the parents playing the role of the child. Parents were encouraged to practice empathic responses and tracking behavior in a similar role play situation with each other. Parents were introduced to the facial expressions of children through still photos of young children expressing various emotions. The homework assignment for the first session was to identify emotions of anger, happiness, sadness, and surprise in their child of focus and make a reflective response. (Handout in Appendix D) Responses were written down for reporting to the group.

\section{Training Session Two}

Session two began with a review of homework assignments. Empathic responding was elaborated on and the facilitator demonstrated empathic responding with a volunteer followed by viewing of a video tape of the facilitator in a play session with a child. Parents were given the opportunity to role play with selected toys in pairs, taking turns being the parent and the child. Parents were given a list of toys (play dough, crayons, paper, blunt scissors, nursing bottle, baby doll, rubber knife, dart gun, doll family, toy soldiers, car, Lone 
Ranger type mask, Tinkertoys, doctor kit, Band-Aids, play money, rope, transparent tape, bop bag, bowling pins, ball, and cardboard box to be used as doll house and container for toys). The facilitator demonstrated each toy and explained the toy's purpose in the special sessions. The homework assignment was to select a time and an uninterrupted place in the home suitable for the play sessions.

\section{Training Session Three}

During session three, the parents were asked to report on arrangements for their sessions. The facilitator reiterated the importance of developing trust through consistency with children in order to enhance the parent-child relationship. Play therapy skills were taught through role playing with toys. The facilitator conducted a live demonstration play session with one of the parent's child who was not the "child of focus". The facilitator explained techniques used and answered questions following the demonstration. Parents were given filial kits as described in session two. The homework assignment was to help the child make a "Play Session - Do Not Disturb" sign to hang on the door and to have the first of their weekly play sessions. Parents were given a list of play time rules (see Appendix D). One parent was asked to volunteer to be video tape his or her play session that week at home for demonstration purposes and feedback at the next group meeting.

\section{Training Session Four}

During session four, the parents were asked to report on their first play 
sessions. Areas of difficulty were discussed with suggestions offered by the facilitator. The homework assignment was for parents to continue home play sessions and to notice one intense feeling in themselves.

\section{Training Sessions Five Through Nine}

Sessions five through nine followed the same general format as session four. Brief reporting by the parents of their play sessions was interspersed with suggestions and instruction from the therapist along with group interaction on common problems and attention to parents' feelings. A parent video tape was viewed and discussed during each session. Homework assignments in which responses were written to typical happenings in play sessions were critiqued. Training and role playing of play session principles and skills was continued each session.

\section{Training Session Five}

Limit-setting was discussed using the handout "Two Techniques of Discipline that Work". Parents were invited to discuss the feelings they experienced during the play session with their child that week. The "sandwich hug" was demonstrated and parents were asked to practice "sandwich hugs" and to practice giving their child one choice during the week.

\section{Training Session Six}

The handout "When Setting Limits Doesn't Work" was discussed. Parents were asked to write notes to all of their children following the format outlined in the manual for Session \#6 (Appendix D). The importance of 
focussing on one child during this training period was reiterated. Parents were asked to notice any patterns that were emerging in their child's play sessions.

\section{Training Session Seven}

The facilitator reviewed reflective listening, setting limits, and giving choices. Parents were given the opportunity to practice their skills in role play. Parents shared the progress they had made in play sessions. The parents were asked to notice the number of times they touched their child during the week.

\section{Training Session Eight}

The amount of physical interaction between parents and children was discussed. Parents debriefed their play sessions. The facilitator focused on parents accepting themselves and their children, allowing themselves and their children to make mistakes and be imperfect.

\section{Training Session Nine}

After play session debriefing, the facilitator asked parents to write down questions to be discussed during the final training session. Follow-up meetings were discussed with group members. Parents were encouraged to consider any changes they had seen in themselves and their children.

\section{Training Session Ten}

Parents reported on their play sessions. The facilitator shared notes of: parents' original descriptions of their children as points of reference for parents to evaluate progress. The parents shared their evaluation of the experience and how they and their children had changed. The rules of thumb and other things 
to remember were discussed, with an emphasis on how play sessions could continue and change over time. Parents were encouraged to continue play sessions with their child of focus and use play sessions with other children in the family. Parents completed the post-test battery of instruments comprised of the Child Behavior Checklist, the Parenting Stress Index, and the Porter Parental Acceptance Scale.

\section{Facilitator}

The filial therapy training groups were facilitated by the investigator of this study. The investigator is a Nationally Certified Counselor and a doctoral candidate at the University of North Texas with a Master's degree in Counseling. She had completed an introduction to play therapy course, an advanced play therapy course, and a filial therapy course. In addition she had received supervision of play therapy experiences in a master's degree practicum, a doctoral level practicum in play therapy, and a doctoral internship in play therapy. She had provided play therapy supervision for masters and doctoral level students. She had also conducted previous filial therapy training and supervision.

Parents from the control group were offered filial therapy training facilitated by interns trained in play therapy and filial therapy at the Child and Family Resource Clinic at the University of North Texas after the completion of the first series. The investigator was available to the interns facilitating the filial groups for consultation as necessary during the second series of classes. 


\section{Statistical Analyses}

Following the collection of the pretest and post-test data, the three selfreport instruments from the parents were blind-scored by the researcher and double-checked by a research assistant. The teacher rated instrument was also blind-scored by the researcher and double-checked by a research assistant.

For the purpose of statistical analysis, data from all the filial therapy training groups was pooled to form the experimental group. The resulting data was keyed into the computer and analyzed by the researcher using SPSS (1993).

An analysis of covariance (ANCOVA) was computed to test the significance of the difference between the experimental group and the control group on the adjusted post-test means for each hypotheses. In each case the post-test specified in each of the hypotheses was used as the dependent variable and the pretest as the covariate. ANCOVA was used to adjust the group means on the post-test on the basis of the pretest, thus statistically equating the control and experimental groups. Significance of difference between means was tested using .05 as the level of significance. On the basis of the ANCOVA, the hypotheses were either retained or rejected. 


\section{CHAPTER III}

\section{RESULTS AND DISCUSSION}

This chapter presents the results of the analysis of the data for each hypothesis tested in this study. Included also is a discussion of the results, implications, and recommendations for further research.

Results

The results of this study are presented in the order the hypotheses were tested. Analyses of covariance were performed on all hypotheses and a level of significance of .05 was established as the criterion for either retaining or rejecting the hypotheses.

\section{Hypothesis 1}

The experimental group parents will attain a significantly higher mean total score on the Porter Parental Acceptance Scale (PPAS) post-test than will the control group parents.

Table 1 presents the pre and post-test means and standard deviations for the experimental and control groups. Table 2 presents the analysis of covariance data, showing that there is a significant difference between the experimental and control groups' post-test mean scores. 
Table 1.

Mean total scores for the Porter Parental Acceptance Scale (PPAS)

\begin{tabular}{lccccc}
\hline \hline & \multicolumn{2}{c}{ Experimental $(n=11)$} & & \multicolumn{2}{c}{ Control $(n=11)$} \\
& Pretest & Post-test & & Pretest & Post-test \\
\hline Mean & 135.5455 & 157.1818 & 140.9091 & 142.3636 \\
SD & 19.070 & 16.816 & 18.234 & 14.569 \\
Total cases $=22$ & & & & \\
\hline
\end{tabular}

Table 2.

Analysis of covariance data for the mean total scores for the (PPAS)

\begin{tabular}{llllll}
\hline \hline $\begin{array}{l}\text { Source of } \\
\text { Variation }\end{array}$ & $\begin{array}{l}\text { Sum of } \\
\text { Squares }\end{array}$ & df & Mean & S & Sign. \\
\hline Main effects & 1682.876 & 1 & 1682.876 & 10.822 & .004 \\
Covariates & 1995.589 & 1 & 1995.589 & 12.833 & .002 \\
Error & 6157.864 & 21 & 293.232 & & \\
Total cases $=22$ & & & & & \\
\hline
\end{tabular}

Table 2 shows the $E$ ratio for the main effects was significant to the .004 level indicating a significant increase in the experimental group parents' mean total scores for the Porter Parental Acceptance Scale (PPAS). On the basis of this data, hypothesis 1 was retained.

Hypothesis 1.a

The experimental group parents will attain a significantly higher mean score on the "Respect for the Child's Feelings and Right to Express Them" 
subscale of the PPAS post-test than will the control group parents.

Table 3 presents the pre and post-test means and standard deviations for the experimental and control groups. Table 4 presents the analysis of covariance data, showing that there is a significant difference between the experimental and control groups' post-test mean scores.

Table 3.

Mean scores for the (PPAS) subscale: Respect for the Child's Feelings and Right to Express Them

\begin{tabular}{lcccc}
\hline & \multicolumn{2}{c}{ Experimental $(n=11)$} & \multicolumn{2}{c}{ Control $(n=11)$} \\
& Pretest & Post-test & Pretest & Post-test \\
\hline Mean & 32.3636 & 39.9091 & 31.0000 & 30.7273 \\
SD & 6.637 & 7.489 & 8.000 & 6.198 \\
Total cases $=22$ & & & & \\
\hline
\end{tabular}

Table 4.

Analysis of covariance data for the mean scores on the (PPAS) subscale:

Respect for the Child's Feelings and Right to Express Them

\begin{tabular}{|c|c|c|c|c|c|}
\hline $\begin{array}{l}\text { Source of } \\
\text { Variation }\end{array}$ & $\begin{array}{l}\text { Sum of } \\
\text { Squares }\end{array}$ & $d f$ & $\begin{array}{l}\text { Mean } \\
\text { Square }\end{array}$ & $\begin{array}{l}\mathrm{E} \\
\text { Ratio }\end{array}$ & $\begin{array}{l}\text { Sign. } \\
\text { of } F\end{array}$ \\
\hline Main effects & 400.447 & 1 & 400.447 & 10.426 & .004 \\
\hline Covariates & 215.331 & 1 & 215.331 & 5.606 & .029 \\
\hline Error & 1408.773 & 21 & 67.084 & & \\
\hline \multicolumn{6}{|c|}{ Total cases $=22$} \\
\hline
\end{tabular}


Table 4 shows the $E$ ratio for the main effects was significant to the .004 level indicating a significant increase in the experimental group parents' mean total scores for the (PPAS) subscale: Respect for the Child's Feelings and Right to Express Them. On the basis of this data, hypothesis 1.a was retained.

Hypothesis 1.b

The experimental group parents will attain a significantly higher mean score on the "Appreciation of the Child's Unique Makeup" subscale of the PPAS post-test than will the control group parents.

Table 5 presents the pre and post-test means and standard deviations for the experimental and control groups. Table 6 presents the analysis of covariance data, showing that there is a significant difference between the experimental and control groups' post-test mean scores.

Table 5.

Mean scores for the (PPAS) subscale: Appreciation of the Child's Unique Makeup

\begin{tabular}{lcccc}
\hline & \multicolumn{2}{c}{ Experimental $(n=11)$} & \multicolumn{2}{c}{ Control $(n=11)$} \\
& Pretest & Post-test & Pretest & Post-test \\
\hline Mean & 34.7273 & 37.8182 & 32.7273 & 32.1818 \\
SD & 4.798 & 5.363 & 5.042 & 5.492 \\
Total cases $=22$ & & & & \\
\hline
\end{tabular}


Table 6.

Analysis of covariance data for the mean scores on the (PPAS) subscale:

Appreciation of the Child's Unique Makeup

\begin{tabular}{lrrrrr}
\hline Source of & Sum of & & Mean & E & Sign. \\
Variation & Squares & df & Square & Ratio & of F \\
Main effects & 99.653 & 1 & 99.653 & 4.860 & .040 \\
Covariates & 199.687 & 1 & 199.687 & 9.739 & .006 \\
Error & 764.000 & 21 & 36.381 & & \\
Total cases $=22$ & & & & & \\
\hline
\end{tabular}

Table 6 shows the $E$ ratio for the main effects was significant to the .040 level indicating a significant increase in the experimental group parents' mean total scores for the (PPAS) subscale: Appreciation of the Child's Unique Makeup. On the basis of this data, hypothesis 1.b was retained.

Hypothesis 1.6

The experimental group parents will attain a significantly higher mean score on the "Recognition of the Child's Needs for Autonomy and Independence" subscale of the PPAS post-test than will the control group parents.

Table 7 presents the pre and post-test means and standard deviations for the experimental and control groups. Table 8 presents the analysis of covariance data, showing that there is a significant difference between the experimental and control groups' post-test mean scores. 
Table 7.

Mean scores for the (PPAS) subscale: Recognition of the Child's Need for Autonomy and Independence

\begin{tabular}{lcccc}
\hline \hline & \multicolumn{2}{c}{ Experimental $(n=11)$} & \multicolumn{2}{c}{ Control $(n=11)$} \\
& Pretest & Post-test & Pretest & Post-test \\
\hline Mean & 37.7273 & 43.3636 & 39.7273 & 40.0909 \\
SD & 4.941 & 3.202 & 4.606 & 3.506 \\
Total cases $=22$ & & & & \\
\hline
\end{tabular}

Table 8.

Analysis of covariance data for the mean scores on the (PPAS) subscale:

Recognition of the Child's Need for Autonomy and Independence

\begin{tabular}{lrrrrr}
\hline \hline Source of & Sum of & & Mean & $\mathrm{E}$ & Sign. \\
Variation & Squares & $\mathrm{df}$ & Square & Ratio & of F \\
Main effects & 93.095 & 1 & 93.095 & 14.177 & .001 \\
Covariates & 100.691 & 1 & 100.691 & 15.334 & .001 \\
Error & 284.364 & 21 & 13.541 & & \\
Total cases $=22$ & & & & & \\
\hline
\end{tabular}

Table 8 shows the $E$ ratio for the main effects was significant to the .001 level indicating a significant increase in the experimental group parents' mean total scores for the (PPAS) subscale: Recognition of the Child's Need for Autonomy and Independence. On the basis of this data, hypothesis 1.c was retained. 
Hypothesis 1d

The experimental group parents will attain a significantly higher mean score on the "Unconditional Love" subscale of the PPAS post-test than will the control group parents.

Table 9 presents the pre and post-test means and standard deviations for the experimental and control groups. Table 10 presents the analysis of covariance data, showing that there is no significant difference between the experimental and control groups' post-test mean scores.

Table 9.

Mean scores for the (PPAS) subscale: Unconditional Love

\begin{tabular}{lcccc}
\hline \hline & \multicolumn{2}{c}{ Experimental $(n=11)$} & \multicolumn{2}{c}{ Control $(n=11)$} \\
& Pretest & Post-test & Pretest & Post-test \\
\hline Mean & 30.7273 & 36.0909 & 37.4545 & 39.3636 \\
SD & 11.464 & 9.492 & 5.733 & 7.487 \\
Total cases $=22$ & & & & \\
\hline
\end{tabular}

Table 10.

Analysis of covariance data for the mean scores on the (PPAS) subscale: Unconditional Love

\begin{tabular}{|c|c|c|c|c|c|}
\hline $\begin{array}{l}\text { Source of } \\
\text { Variation }\end{array}$ & $\begin{array}{l}\text { Sum of } \\
\text { Squares }\end{array}$ & $\mathrm{df}$ & $\begin{array}{l}\text { Mean } \\
\text { Square }\end{array}$ & $\begin{array}{l}\text { E } \\
\text { Ratio }\end{array}$ & $\begin{array}{l}\text { Sign. } \\
\text { of } F\end{array}$ \\
\hline Main effects & .038 & 1 & .038 & .001 & .980 \\
\hline Covariates & 367.906 & 1 & 367.906 & 6.392 & .020 \\
\hline Error & 1520.364 & 21 & 72.398 & & \\
\hline Total cases $=22$ & & & & & \\
\hline
\end{tabular}


Table 10 shows the $E$ ratio for the main effects was significant to the .980 level indicating no significant increase in the experimental group parents' mean total scores for the (PPAS) subscale: Unconditional Love. On the basis of this data, hypothesis $1 . d$ was not retained.

\section{Hypothesis 2}

The experimental group parents will attain a significantly lower mean total score on the Parenting Stress Index (PSI) post-test than will the control group parents.

Table 11 presents the pre and post-test means and standard deviations for the experimental and control groups. Table 12 presents the analysis of covariance data, showing that there is a significant difference between the experimental and control groups' post-test mean scores.

\section{Table 11.}

Mean scores for the Parenting Stress Index (PSI)

\begin{tabular}{lcccc}
\hline \hline & \multicolumn{2}{l}{ Experimental $(n=11)$} & \multicolumn{2}{c}{ Control $(n=11)$} \\
& Pretest & Post-test & Pretest & Post-test \\
\hline Mean & 246.0000 & 220.9091 & 250.5455 & 247.0000 \\
SD & 25.760 & 32.574 & 62.904 & 53.136 \\
Total cases $=22$ & & & & \\
\hline
\end{tabular}


Table 12.

Analysis of covariance data for the mean scores for the (PSI)

\begin{tabular}{llrrrrr}
\hline \multicolumn{1}{c}{ Source of } & Sum of & & Mean & E & Sign. \\
Variation & Squares & df & Square & Ratio & of F \\
Main effects & 2764.679 & 1 & 2764.679 & 5.732 & .027 \\
Covariates & 29680.275 & 1 & 29680.275 & 61.533 & .000 \\
Error & 42588.955 & 21 & 2028.045 & & \\
Total cases $=22$ & & & & & \\
\hline
\end{tabular}

Table 12 shows the $E$ ratio for the main effects was significant to the .027 level indicating a significant increase in the experimental group parents' mean total scores for the Parenting Stress Index (PSI). On the basis of this data, hypothesis 2 was retained.

Hypothesis 2.a

The experimental group parents will attain a significantly lower mean score on the "Parent Domain" of the PSI post-test than will the control group parents.

Table 13 presents the pre and post-test means and standard deviations for the experimental and control groups. Table 14 presents the analysis of covariance data, showing that there is a significant difference between the experimental and control groups' post-test mean scores. 
Table 13.

Mean scores for the (PSI) subscale: Parent Domain

\begin{tabular}{|c|c|c|c|c|}
\hline & \multicolumn{2}{|c|}{ Experimental $(n=11)$} & \multicolumn{2}{|c|}{ Control $(n=11)$} \\
\hline & Pretest & Post-test & Pretest & Post-test \\
\hline Mean & 127.6364 & 114.2727 & 130.0909 & 132.2727 \\
\hline$\underline{\mathrm{SD}}$ & 13.178 & 16.193 & 34.847 & 29.176 \\
\hline Total & & & & \\
\hline
\end{tabular}

Table 14.

Analysis of covariance data for the mean scores for the (PSI) subscale: Parent Domain

\begin{tabular}{lrrrrr}
\hline \hline Source of & Sum of & & Mean & $E$ & Sign. \\
Variation & Squares & df & Square & Ratio & of F \\
Main effects & 1436.791 & 1 & 1436.791 & 7.754 & .012 \\
Covariates & 7613.747 & 1 & 7613.747 & 41.090 & .000 \\
Error & 12916.364 & 21 & 615.065 & & \\
Total cases $=22$ & & & & & \\
\hline
\end{tabular}

Table 14 shows the $E$ ratio for the main effects was significant to the 012 level indicating a significant increase in the experimental group parents' mean total scores for the (PSI) subscale: Parent Domain. On the basis of this data, hypothesis 2.a was retained. 
Hypothesis 2.b

The experimental group parents will attain a significantly lower mean score on the "Child Domain" of the PSI post-test than will the control group parents.

Table 15 presents the pre and post-test means and standard deviations for the experimental and control groups. Table 16 presents the analysis of covariance data, showing that there is no significant difference between the experimental and control groups' post-test mean scores.

Table 15.

Mean scores for the (PSI) subscale: Child Domain

\begin{tabular}{lcccc}
\hline & \multicolumn{2}{c}{ Experimental $(n=11)$} & \multicolumn{2}{c}{ Control $(n=11)$} \\
& Pretest & Post-test & Pretest & Post-test \\
\hline Mean & 118.3636 & 106.9091 & 120.4545 & 114.7273 \\
SD & 15.819 & 21.097 & 32.238 & 27.004 \\
Total cases $=22$ & & & & \\
\hline
\end{tabular}

Table 16.

Analysis of covariance data for the mean scores for the (PSI) subscale: Child Domain

\begin{tabular}{|c|c|c|c|c|c|}
\hline $\begin{array}{l}\text { Source of } \\
\text { Variation }\end{array}$ & $\begin{array}{l}\text { Sum of } \\
\text { Squares }\end{array}$ & $\mathrm{df}$ & $\begin{array}{l}\text { Mean } \\
\text { Square }\end{array}$ & $\begin{array}{l}\mathrm{E} \\
\text { Ratio } \\
\end{array}$ & $\begin{array}{l}\text { Sign. } \\
\text { of } F\end{array}$ \\
\hline Main effects & 204.565 & 1 & 204.565 & 1.262 & .275 \\
\hline Covariates & 8663.573 & 1 & 8663.573 & 53.452 & .000 \\
\hline Error & 12079.273 & 21 & 575.203 & & \\
\hline \multicolumn{6}{|c|}{ Total cases $=22$} \\
\hline
\end{tabular}


Table 16 shows the E ratio for the main effects was significant to the .275 level indicating no significant increase in the experimental group parents' mean total scores for the (PSI) subscale: Child Domain. On the basis of this data, hypothesis $2 . b$ was not retained.

Hypothesis 3

The experimental group children will attain a significantly lower mean total score on Externalizing Behavior Problems as indicated on the Parent Report Form of the Child Behavior Checklist at post-testing than will the control group children.

Table 17 presents the pre and post-test means and standard deviations for the experimental and control groups. Table 18 presents the analysis of covariance data, showing that there is not a significant difference between the experimental and control groups' post-test mean scores.

Table 17.

Mean scores for Externalizing Behavior Problems on the Parent Report Form of the Child Behavior Checklist

\begin{tabular}{lcccc}
\hline \hline & \multicolumn{2}{c}{ Experimental $(n=11)$} & \multicolumn{2}{c}{ Control $(n=11)$} \\
& Pretest & Post-test & Pretest & Post-test \\
\hline \multirow{2}{*}{ Mean } & 13.9091 & 10.5455 & 14.1818 & 12.7273 \\
SD & 7.700 & 7.776 & 11.321 & 11.559 \\
Total cases $=22$ & & & & \\
\hline
\end{tabular}


Table 18.

Analysis of covariance data for the mean scores on Externalizing Behavior Problems on the Parent Report form of the Child Behavior Checklist

\begin{tabular}{|c|c|c|c|c|c|}
\hline $\begin{array}{l}\text { Source of } \\
\text { Variation }\end{array}$ & $\begin{array}{l}\text { Sum of } \\
\text { Squares }\end{array}$ & df & $\begin{array}{l}\text { Mean } \\
\text { Square }\end{array}$ & $\begin{array}{l}\text { E } \\
\text { Ratio } \\
\end{array}$ & $\begin{array}{l}\text { Sign. } \\
\text { of. } F\end{array}$ \\
\hline Main effects & 20.281 & 1 & 20.281 & 1.752 & .201 \\
\hline Covariates & 1720.920 & 1 & 1720.920 & 148.632 & .000 \\
\hline Error & 1967.091 & 21 & 93.671 & & \\
\hline Total cases $=22$ & & & & & \\
\hline
\end{tabular}

Table 18 shows the $\mathrm{E}$ ratio for the main effects was significant to the .201 level indicating no significant decrease in the experimental group children's' Externalizing Behavior Problems score for the Parent Report Form of the Child Behavior Checklist. On the basis of this data, hypothesis 3 was not retained. Hypothesis 4

The experimental group children will attain a significantly lower mean score on Internalizing Behavior Problems as indicated on the Parent Repont Form of the Child Behavior Checklist at post-testing than will the control group children.

Table 19 presents the pre and post-test means and standard deviations for the experimental and control groups. Table 20 presents the analysis of covariance data, showing that there is not a significant difference between the experimental and control groups' post-test mean scores. 
Table 19.

Mean scores for Internalizing Behavior Problems on the Parent Report Form of the Child Behavior Checklist

\begin{tabular}{lllll}
\hline & \multicolumn{2}{l}{ Experimental $(n=11)$} & \multicolumn{2}{c}{ Control $(n=11)$} \\
& Pretest & Post-test & Pretest & Post-test \\
\hline Mean & 8.4545 & 5.2727 & 11.3636 & 7.5455 \\
SD & 5.165 & 5.368 & 7.173 & 5.922 \\
Total cases $=22$ & & & & \\
\hline
\end{tabular}

Table 20.

Analysis of covariance data for the mean scores for Internalizing Behavior Problems on the Parent Form of the Child Behavior Checklist

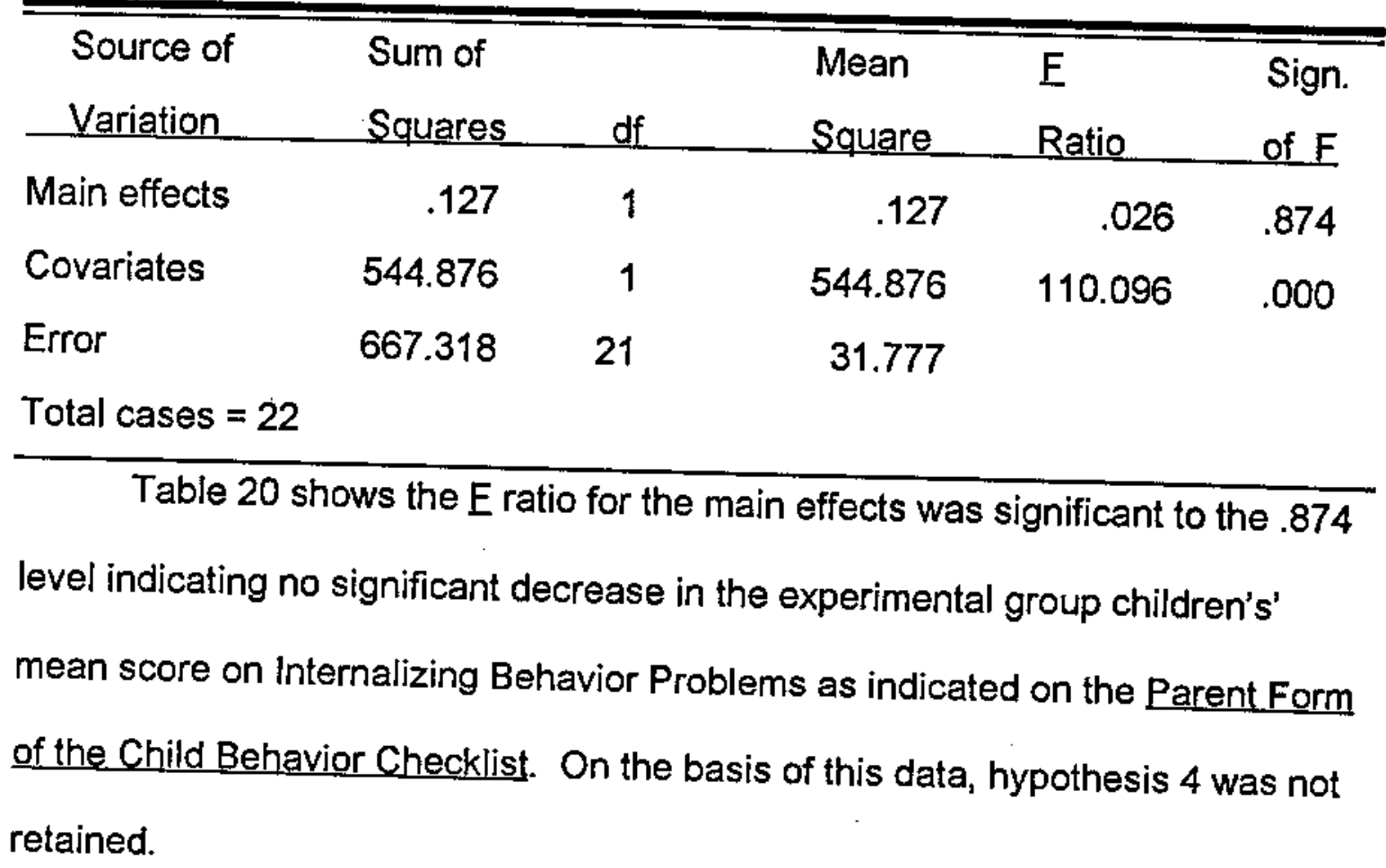


Hypothesis 5

The experimental group children will attain a significantly lower mean score on Total Behavior Problems as indicated on the ParentForm of the Child Behavjor Checklist at post-testing than will the control group children.

Table 21 presents the pre and post-test means and standard deviations for the experimental and control groups. Table 22 presents the analysis of covariance data, showing that there is not a significant difference between the experimental and control groups' post-test mean scores.

Table 21.

Mean scores for Total Behavior Problems on the Parent Form of the Child Behavior Checklist

\begin{tabular}{lllll}
\hline \hline & \multicolumn{2}{c}{ Experimental $(n=11)$} & \multicolumn{2}{c}{ Control $(n=11)$} \\
& Pretest & Post-test & Pretest & Post-test \\
\hline Mean & 38.6364 & 27.8182 & 39.8182 & 32.5455 \\
SD & 16.651 & 19.508 & 25.799 & 20.997 \\
Total cases $=22$ & & & & \\
\hline
\end{tabular}

Table 22.

Analysis of covariance data for the mean scores for Total Behavior Problems on the Parent Form of the Child Behavior Checklist

\begin{tabular}{|c|c|c|c|c|c|}
\hline $\begin{array}{l}\text { Source of } \\
\text { Variation }\end{array}$ & $\begin{array}{l}\text { Sum of } \\
\text { Squares }\end{array}$ & $\mathrm{df}$ & $\begin{array}{l}\text { Mean } \\
\text { Square }\end{array}$ & $\begin{array}{l}\text { E } \\
\text { Ratio }\end{array}$ & $\begin{array}{l}\text { Sign. } \\
\text { of } E\end{array}$ \\
\hline Main effects & 75.698 & 1 & 75.698 & 1.153 & .296 \\
\hline Covariates & 6966.424 & 1 & 6966.424 & 106.064 & .000 \\
\hline $\begin{array}{l}\text { Error } \\
\text { Total cases }=22\end{array}$ & 8337.273 & 21 & 397.013 & & \\
\hline
\end{tabular}


Table 22 shows the $E$ ratio for the main effects was significant at the .296 level indicating no significant decrease in the experimental group children's Total Behavior Problems as indicated on the Parent Form of the Child Behavior Checklist. On the basis of this data, hypothesis 5 was not retained. Hypothesis 6

The experimental group children will attain a significantly lower mean score on Externalizing Behavior Problems as indicated on the Teacher Report Form of the Child Behavior Checklist at post-testing than will the control group children.

Table 23 presents the pre and post-test means and standard deviations for the experimental and control groups. Table 24 presents the analysis of covariance data, showing that there is not a significant difference between the experimental and control groups' post-test mean scores.

Table 23.

Mean scores for Externalizing Behavior Problems on the Teacher Report Form of the Child Behavior Checklist

\begin{tabular}{llccc}
\hline \hline & \multicolumn{2}{c}{ Experimental $(n=10)$} & \multicolumn{2}{c}{ Control $(n=11)$} \\
& Pretest & Post-test & Pretest & Post-test \\
\hline \multirow{2}{*}{ Mean } & 19.50000 & 11.7000 & 13.2727 & 11.5455 \\
SD & 19.643 & 15.938 & 14.974 & 13.714 \\
Total cases $=21$ & & & & \\
\hline
\end{tabular}


Table 24.

Analysis of covariance data for the mean scores for Externalizing Behavior

Problems on the Teacher Report Form of the Child Behavior Checklist

\begin{tabular}{|c|c|c|c|c|c|}
\hline $\begin{array}{l}\text { Source of } \\
\text { Variation }\end{array}$ & $\begin{array}{l}\text { Sum of } \\
\text { Squares }\end{array}$ & $d f$ & $\begin{array}{l}\text { Mean } \\
\text { Square }\end{array}$ & $\begin{array}{l}\mathbf{E} \\
\text { Ratio }\end{array}$ & $\begin{array}{l}\text { Sign. } \\
\text { of } F\end{array}$ \\
\hline Main effects & 102.205 & 1 & 102.205 & 1.875 & .188 \\
\hline Covariates & 3185.851 & 1 & 3185.851 & 58.457 & .000 \\
\hline Error & 4166.952 & 20 & 208.348 & & \\
\hline \multicolumn{6}{|c|}{ Total cases $=21$} \\
\hline
\end{tabular}

Table 24 shows the $\mathrm{E}$ ratio for the main effects was significant to the .188 level indicating no significant decrease in the experimental group children's' mean score on Externalizing Behavior Problems as indicated on the Teacher Report for of the Child Behavior Checklist. On the basis of this data, hypothesis 6 was not retained.

Hypothesis 7

The experimental group children will attain a significantly lower mean score on Internalizing Behavior Problems as indicated on the Teacher Report form of the Child Behavior Checklist at post-testing than will the control group children.

Table 25 presents the pre and post-test means and standard deviations for the experimental and control groups. Table 26 presents the analysis of covariance data, showing that there is no significant difference between the experimental and control groups' post-test mean scores. 
Table 25.

Mean scores on Internalizing Behavior Problems on the Teacher Report Form of the Child Behavior Checklist

\begin{tabular}{lclcl}
\hline & \multicolumn{2}{c}{ Experimental $(n=10)$} & \multicolumn{2}{c}{ Control $(n=11)$} \\
& Pretest & Post-test & Pretest & Post-test \\
\hline Mean & 12.4000 & 6.9000 & 10.9091 & 8.8182 \\
SD & 9.240 & 9.398 & 7.231 & 6.431 \\
Total cases $=21$ & & & & \\
\hline
\end{tabular}

Table 26.

Analysis of covariance data for the mean scores on Internalizing Behavior Problems on the Teacher Report Form of the Child Behavior Checklist

\begin{tabular}{|c|c|c|c|c|c|}
\hline $\begin{array}{l}\text { Source of } \\
\text { Variation }\end{array}$ & $\begin{array}{l}\text { Sum of } \\
\text { Squares }\end{array}$ & df & $\begin{array}{l}\text { Mean } \\
\text { Square }\end{array}$ & $\begin{array}{l}\mathrm{E} \\
\text { Ratio } \\
\end{array}$ & $\begin{array}{l}\text { Sign. } \\
\text { of } F\end{array}$ \\
\hline Main effects & 52.776 & 1 & 52.776 & 3.504 & .078 \\
\hline Covariates & 937.405 & 1 & 937.405 & 62.233 & .000 \\
\hline Error & 1227.810 & 20 & 61.390 & & \\
\hline \multicolumn{6}{|c|}{ Total cases $=21$} \\
\hline
\end{tabular}

Table 26 shows the $\mathrm{E}$ ratio for the main effects was significant to the .078 level indicating no significant decrease in the experimental group children's mean score on Internalizing Behavior Problems as indicated on the Teacher Report form of the Child Behavior Checklist. On the basis of this data, hypothesis 7 was not retained. 
Hypothesis 8

The experimental group children will attain a significantly lower mean score on Total Behavior Problems on the Teacher Report form of the Child Behavior Checklist at post-testing than will the control group children.

Table 27 presents the pre and post-test means and standard deviations for the experimental and control groups. Table 28 presents the analysis of covariance data, showing that there is no significant difference between the experimental and control groups' post-test mean scores.

Table 27.

Mean scores on Total Behavior Problems on the Teacher Report form of the Child Behavior Checklist

\begin{tabular}{lllll}
\hline \hline & \multicolumn{2}{c}{ Experimental $(n=10)$} & \multicolumn{2}{c}{ Control $(n=11)$} \\
& Pretest & Post-test & Pretest & Post-test \\
\hline Mean & 58.7000 & 39.1000 & 40.5455 & 34.8182 \\
SD & 41.207 & 39.071 & 35.427 & 32.003 \\
Total cases $=21$ & & & & \\
\hline
\end{tabular}

Table 28.

Analysis of covariance data for the mean scores on Total Behavior Problems on the Teacher Report form of the Child Behavior Checklist

\begin{tabular}{llrllll}
\hline \multicolumn{1}{c}{$\begin{array}{c}\text { Source of } \\
\text { Variation }\end{array}$} & $\begin{array}{l}\text { Sum of } \\
\text { Squares }\end{array}$ & df & & $\begin{array}{l}\text { Mean } \\
\text { Square }\end{array}$ & $\begin{array}{l}\text { R } \\
\text { Ratio }\end{array}$ & $\begin{array}{l}\text { Sign. } \\
\text { of F }\end{array}$ \\
\hline Main effects & 580.398 & 1 & & 580.398 & 2.247 & .151 \\
Covariates & 19330.633 & 1 & 19330.633 & 74.830 & .000 \\
Error & 24076.571 & 20 & 1203.829 & & \\
Total cases $=21$ & & & & & \\
\hline
\end{tabular}


Table 28 shows the $E$ ratio for the main effects was significant to the .151 level indicating no significant decrease in the experimental group children's mean Total Behavior Problems score as indicated on the Teacher Report for the Child Behavior Checklist. On the basis of this data, hypothesis 8 was not retained.

\section{Discussion}

The results of this study along with parents' comments and the facilitator's observations provide information regarding filial therapy training as an intervention with the parents of children experiencing learning difficulties. Of the 14 separate parts listed as hypotheses, six were retained and eight were rejected. However, all measures showed positive trends even though not at the .05 level of significance. An interpretation of all scores is provided in the following section.

\section{Parental Acceptance}

As can be seen in Table 1 through Table 10, the members of the experimental parent group demonstrated significant positive gains in their perceived acceptance of their children as measured by the total score and three of the four subscales measured by the Porter Parental Acceptance Scale (PPAS). The parents reported significant growth in the areas of "Respect for the Child's Feelings and Right to Express Them", "Appreciation of the Child's Unique Makeup" and "Recognition of the Child's Need for Autonomy and Independence". The parents did not report significant increases in the area of 
"Unconditional Love". The significant increases reported in the first three areas may be attributed to the fact that these areas are more closely related to specific play therapy skills that the parents were required to practice during training. The lack of a significant increase in the area of unconditional love may be attributed to the fact that parents began to perceive their child more as who the child actually was rather than their image of the "ideal" child. In the tenth week of training, several parents commented that they felt liberated in that they now viewed their children as separate people who were responsible for their own actions. One parent commented: "I just feel so free, he can choose to do something and I can let him...it is his responsibility and I don't have to make sure everything is perfect...he seems to be accepting responsibility and even liking it..."

The results on the PPAS suggest that a ten week filial therapy training model is effective in increasing overall parental acceptance among parents of children experiencing learning difficulties.

\section{Parental Stress}

As can be seen in Table 11 through Table 16, the experimental group parents showed significant decreases in their mean total scores and parent domain stress scores as measured by the Parenting Stress Index. These changes can be inferred to have been a result of filial therapy training in that parents in the experimental group learned skills to enhance the parent-child relationship and implemented those skills in the 30-minute special play time 
weekly. Parents reported feeling supported and encouraged by group members, resulting in less stress in their parenting role. One parent reported: "Being a parent is a lonely job...it is just such a relief to know l'm not the only one having these problems...I thought I was just a terrible mother and everyone else knew how to help and handle their child..."

Parents in the experimental group cited learning how to give their children choices as being one of the most beneficial skills they had learned. A parent commented: "...I have a way that works now. At the first sign of conflict I give him a choice and he chooses...the last two weeks have been heaven with discipline and with him...there is no guilt on my part, it is his choice..." The experimental group parents commented that they felt more in control of themselves and confident in their abilities as parents.

The experimental parents did not evidence a significant decrease in stress related to their children when compared with the control group. The experimental group parents evidenced positive trends in reduced stress related to their children, however, the control group also evidenced these trends. One possible reason for this similarity may be the timing of the post-testing. Posttests were administered at the end of the school year. Parents and children were beginning to focus on summer break activities and away from school related issues which are stressful for children and families when the child has a learning difficulty.

The results of the Parenting Stress Index suggest that the 10 week model 
of filial therapy (Landreth, 1991) is effective in reducing parental stress as evidenced by the total stress score and the reported stress related to parents' perception of themselves as parents. Filial therapy training has been shown in previous studies to effective in reducing parents' level of stress related to their children's behavior (Bratton, 1994; Chau, 1997; Harris, 1995; Lobaugh, 1992; Tew, 1997; Yeun, 1997) Problematic Behaviors of Children with Learning Difficulties

As indicated by Table 17 through Table 22, the children of the parents in the experimental group did evidence fewer behavior problems as measured by the Child Behavior Checklist-Parent Report, however the results were not significant at the .05 level. A closer examination of the subscales revealed a significant decrease in the mean score on the "Attention Problems" scale. This improvement in the area of attention may be the result of the improved parentchild relationship fostered by filial therapy training.

As indicated by Table 23 through Table 28 , the children of the parents in the experimental group did evidence fewer behavior problems as perceived by their teachers on the Child Behavior Checklist-Teacher Report, however the results were not significant at the .05 level. A closer examination of the subscales revealed a significant decrease in the mean score on the "Anxious/Depressed" scale. There were also notable decreases in "Delinquent Behavior" at a significance level of .077 and "Attention Problems" at a significance level of .108. 
A possible reason for the lack of significance in the overall reduction of behavior problems might be that the children received only seven play sessions with their parent. Seven session may not be a sufficient amount of treatment time for results to become evident to parents and teachers.

The results of the CBCL-Parent Report suggest that the Landreth (1991) 10-week filial therapy training model is effective in decreasing attention problems as perceived by parents. The results of the $\mathrm{CBCL}$-Teacher Report suggest that the Landreth (1991) 10-week filial therapy training model is effective in reducing anxious/depressed behaviors as perceived by the teacher. It is not clear whether filial therapy is effective in reducing delinquent behavior and attention problems as assessed by teacher report.

The results of this study along with the parents comments and facilitator's observations support the use of filial therapy training with the parents of children experiencing learning difficulties. The school experience is a difficult time for all children but especially for children with learning difficulties. The support of an accepting parent who appreciates the unique make up of their child, respects their child's need for autonomy, and allowing their child to express feelings can make the difference between success and failure. As with other filial therapy studies, the Landreth (1991) 10-week filial therapy training model has positively impacted these key areas of the parent-child relationship.

Although a certain level of stress can be a motivator, it can also hinder the development of a positive relationship between parent and child. The 10- 
week filial therapy training proved successful in reducing parents' level of stress which in turn could free them to support their children in the midst of difficulties. When parents feel more competent in their role as parents their level of stress is lowered and relationships with their children improves.

Many of the children in this study had been diagnosed with Attention Deficient Disorder with Hyperactivity (ADHD) and there was a significant decrease in the parents' perception of the children's attention problems. Acknowledging the current concern with $A D H D$, this supports the use of filial therapy with children with this diagnosis. 


\section{Recommendations}

Based on the results of this study, the following recommendations are offered:

1. The utilization of filial therapy training groups as a viable intervention for the parents of children experiencing learning difficulties.

2. Further research in which filial therapy training groups begin the 10 weeks of training during the first month of the school year and offer followup/support meetings conducted every month thereafter until the end of the school year. Then measure the groups with the same instruments utilized in this study.

3. Further research involving teachers being trained in filial therapy principles concurrently with parents receiving filial therapy training.

4. Conduct a replication of this study using both the CBCL and the Filial Problems Checklist.

5. Further research examining changes in the children as perceived by the parent and teacher when the child has received 15 play sessions with the parent prior to gathering post-test data.

6. Further research limiting the population to only children diagnosed with ADHD.

7. Further research comparing the effects of filial therapy between boys with learning difficulties and girls with difficulties.

8. Further research comparing the effectiveness of filial therapy to 
other types of interventions commonly used with children experiencing learning difficulties such as child-centered play therapy, cognitive behavioral play therapy and behavior modification.

\section{Concluding Remarks}

Children who are experiencing learning difficulties face frustration not only in learning but also in relationships. Filial therapy training is an effective intervention which has been found to promote more positive and secure relationships between parents and children. Healthy relationships between parents and children play a vital role in increasing children's' levels of selfesteem and belief in themselves and their abilitjes. Parents of children with learning difficulties perceive their children as having behavioral characteristics that make their parenting role more difficult. Families of children with learning difficulties also have more difficulty with acceptance of the child than do other families. Filial therapy training is an effective way to help parents deal with their own personal stress and issues as they work to help their children. Filial therapy serves as both a prevention and intervention strategy to meet the needs of the family. Parents, by sharing experiences, can learn to perceive their exceptional children in a more positive manner and deal with problems more effectively and realistically.

The group format provides parents an opportunity in which to come together, share their experiences, and receive information and training for forming healthy parent-child relationships. Training the parents of children with 
learning difficulties to become therapeutic agents in their children's lives is an efficient and effective way to significantly improve the future mental health of these children and their families. 
APPENDIX A

PARENTING CLASS INFORMATION AND CONSENT FORMS 


\section{PARENTING CLASS INFORMATION}

You are invited to participate in a study to determine the effectiveness of Filial Therapy training with parents of children with learning difficulties. You will be asked to complete three questionnaires before and after the training. Your child will be interviewed to complete one questionnaire before and after training. You will also be asked to have your child's teacher complete one questionnaire before and after the training.

Filial Therapy is a family skills training program that focuses on enhancing the parent-child relationship. The training will consist of ten weekly sessions, lasting two hours per week. During the sessions, the group leader will be teaching you and other parents some techniques on how to interact with your child in ways that will enhance your child's self-esteem as well as strengthen your relationship with your child. You will be asked to share some insights, feelings, questions, and comments with the other participants in the group, during the sessions. You will also be asked to participate in seven weekly 30minute play sessions at home with your child practicing the techniques being taught in the training sessions. You will be asked to select one of your children (between the ages of 3-10 years) to focus on during the 10 weeks of training.

There is no personal risk or discomfort directly involved with this study. You will be asked to give some of your time, and to be willing to explore some new ideas and feelings related to the parenting of your child. There may be times during the play sessions when your child could express sadness, anger, or frustration. While these sessions cannot avoid these situations, neither will they increase the emotion. In fact, the training should help you deal with these situations more effectively. Your participation and your child's participation is completely voluntarily. You may withdraw at any time without penalty or prejudice.

The information you provide when you answer the questionnaire will be kept confidential. Your name and your child's name will not be disclosed in any publication or discussion of this material. Information obtained from the questionnaires will be recorded with a code number. Only the investigator, Amy Kale, will have a list of participants' names. At the conclusion of this study the list of participants names will be destroyed.

If you are not selected to receive the training during this first training period, your name will be placed on a waiting list and you will be contacted regarding a second section of training which will be offered after the completion of the first 10 -week section.

If you agree to participate, please fill out and sign this consent form. For 
further information, please contact, Amy Kale, researcher, at (817) 565-3864, or Dr. Garry Landreth, Faculty Supervisor, at (817) 565-2916.

\section{PARENTING CLASS Informed Consent}

You are making a decision whether or not to participate in this study. You should sign only when you understand all the information presented on the front of this form and all your questions about the research have been answered to your satisfaction. Your signature indicates that you meet all the requirements for participation as explained by Amy Kale and have decided to participate, having read the information on the front of this form.
Signature of Participant
Age
Date

Name of Child of Focus Age

Child's Legal Guardian (If different than Participant)

Date

Signature of Witness

Date

Signature of Investigator

Date 


\section{CHILD'S FORM}

Informed Consent

I understand that I am going to be part of a project with an adult who takes care of me (mom, dad, or another significant care giver). The adult will be taking some classes to learn how to play with me in some new ways. For seven weeks, I will have special play sessions with this adult in my home for $\mathbf{3 0}$ minutes once each week. I understand that I can stop taking part in this project at any time I choose.

My "mark", or signature, means that I understand what has explained to me and that I am willing to be part of this project.

Signature of Child Date

Name of Child

Age

Signature of Parent

Date

Signature of Investigator

Date 
APPENDIX B

LETTERS OF PERMISSION FROM PARTICIPATING SCHOOLS 
84

Ponder Independent School District

Post Office Box 278 - 501 Shatfiner Street - Ponder. Texas 76259

JANELL WILBANKS Elementary Principal 817.479 .2900

WONAKA WILLIAMS Secretary $817.479-2900$
To whom it may concern:

Amy Kale has permission to conduct research as part of a dissertation study with volunteers from Ponder Elementary School.

Sincerely,

Gaul e Frellianes

Janell Wilbanks Elementary Principal 


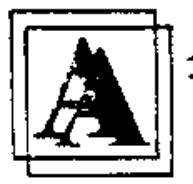

\title{
\begin{tabular}{l} 
AUBREY \\
\hline james A. Shonaco \\
Supenntendent
\end{tabular}
}

\author{
INDEPENDENT SCHOOL DISTRICT \\ 415 Tisdeil jireet \\ Aubrey, Texas -5227 \\ (8I7) 365.2.2:
}

Faculty Advisory Committee

University of North Texas

Department of Counseling, Development and Higher Education

P.O. Box 13857

Denton, TX 76203

To the Committee:

This letter is in support of Amy Kale conducting research as part of a dissertation study with enrolled members of the Aubrey Independent School District who volunteer to participate. It is our understanding that the study will be limited to parent education which teaches parents a structure for special play times with their children. The purpose of these special play sessions is to enhance parent-child relationships.

Sincerely,

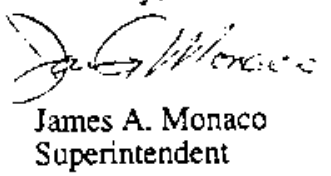

Superintendent

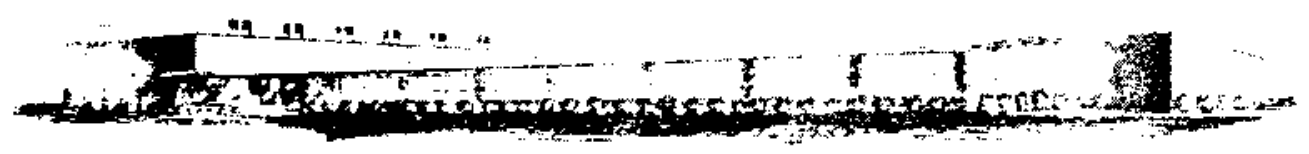


APPENDIX C

MARKETING MATERIALS 


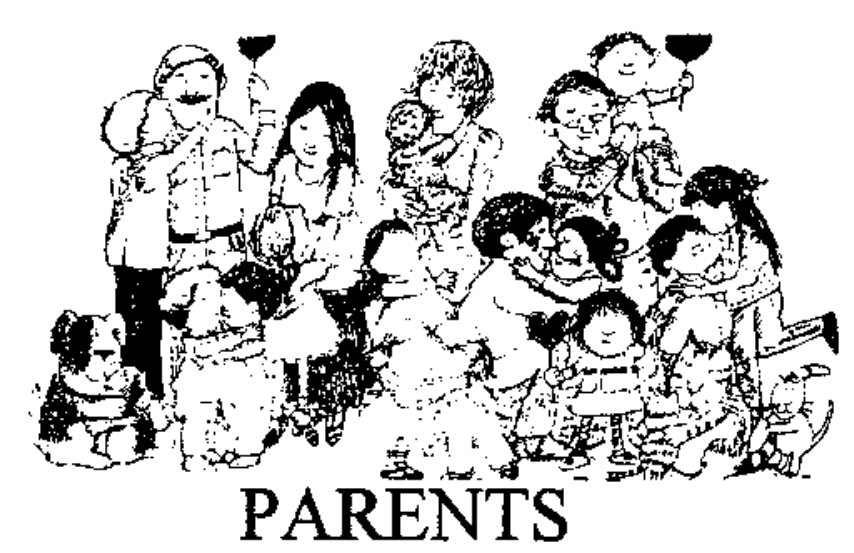

Is your child experiencing

\section{LEARNING DIFFICULTIES?}

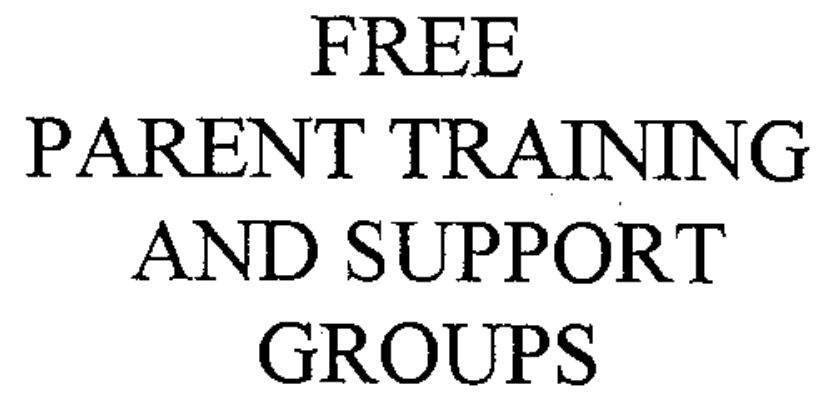

AVAILABLE

What: Do you have a child 3 to 10 years old who is experiencing learning difficulties? Would you like support and training to help your child? Join other parents in a free 10 week training group, called Filial Therapy, led by Amy Kale, a Unjversity of North Texas Ph.D. candidate, who specializes in child and farnily counseling.

Why: Benefits of Filial Therapy training include:

- A better relationship with your child

- A greater understanding of your child and his or her uniquenesses

- A better sense of your abilities as a parent

- An improvement in your child's self-esteem

na Free therapeutic toys are given to participating families***

When: Once a week for 10 consecutive weeks beginning in February.

Where: Ponder Elementary School

Contact: For further information please contact Amy Kaie 817-565-3864 (work) or 817-566-6354 (home).

Enroliment is limited! To reserve your spot please call by January $27,1997$.

Lniversity of North Texas 
If it is more convenient, and you are interested in more information, simply fill out the form at the bottom of this page with your name \& phone number and return to your child's teacher. Amy Kale will contact you with more information.

Yes, I am interested in hearing more about the free Filial Therapy training and toys being offered at Ponder Elementary by Amy Kale.

Parent's Name

Teacher's Name

Parent's Phone Number

Best Times To Call 


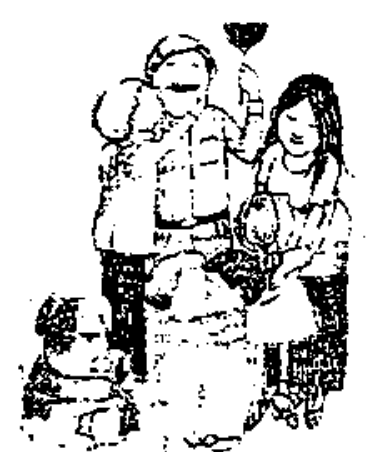

\title{
PARENTS
}

Is your child experiencing

\section{DIFFICULTIES WITH LEARNING?*}

\author{
FREE \\ PARENT TRAINING \\ AND SUPPORT \\ GROUP
}

\section{AVAILABLE}

What: Do you have a child 3 to 10 years old who is experiencing diffectities with learning?* Would you like suppor and training to increase your child's attention span, build your child's self-esteen, help your child leam self-control and make your own parenting easier? Join other parents in a EREE.10 week training group led by Amy Kale, a University of North Texas Ph.D. candidate, who specializes in child and family counseting.

Why: Benefits of Parent-Child Relationship Enhancement Training include:

- A better reiationship with your child

- A greater understanding of your child and his or her uniquenesses

- A berter sense of your abilities as a parent

- An improvement in your child's self-esteem

Free therapeutic toys are given to participating families

When: Once a week for 10 consecutive weeta beginning in February (meeting time will be arranged to fit your schedule)

Where: Aubrey Elementary School

Contact: For further information please contact Amy Kale 817-565-3864 (work), 817-566-6354 (home) or, Delore Jones, school counselor at Aubrey Elementary, at 365-9048. Enrollnent is limited! To reserve your spot please call or send in slip by February 14, 1997.

* Examples of difficuities children sometimes experience that interfere with leaming: not reading as well as other children his/her age; difficulty in math with adding, muitiplication, etc.; difficulties with peers; difficulties accepting discipline; inattention; and oppositional behaviors. 
If it is more convenient, and you are interested in more information, simply fill out the form at the bottom of this page with your name \& phone number and return to your child's teacher. Amy Kale will contact you with more information.

Yes, I am interested in hearing more about the FREE Parent-Child Relationship Enhancement Training and toys being offered at Aubrey Elementary by Amy Kale.

Parent's Name

Teacher's Name

Parent's Phone Number

Best Times To Call

Please list the days of the week and times you would be available to meet with training group (please list atl possibilities, I will use this information in planning a day and time for the group meetings) 


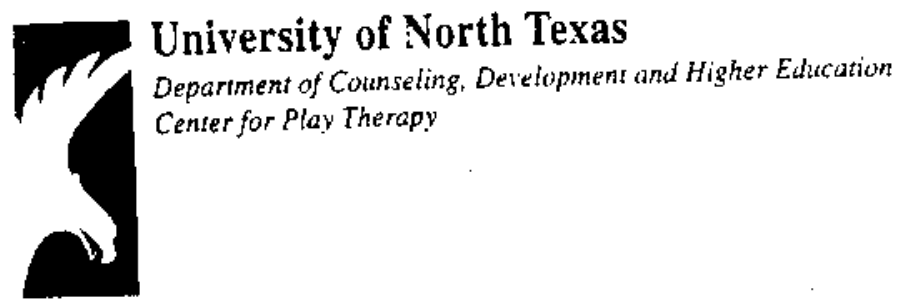

Dear Teacher,

Hello! My name is Amy Kale, I am a Ph.. D. Candidate at the University of North Texas in Counseling and Student Services. I would like to thank you for handing out the flyers concerning the parenting group I will be offering at your school, the response from parents was encouraging! These groups are part of my doctoral research project in which I am measuring the effectiveness of Parent-Child Relationship Enhancement Training (also known as Filial Therapy Training) with parents who perceive that their child is experiencing difficulties with learning. I will ask the parents to complete three instruments before and after the training in hopes of gaining insight into their assessment of their child and any changes that might occur during the next ten weeks. I am also very interested in whether or not you as the child's teacher perceive any changes. I believe that assessing teacher as well as parent perception is essential in looking at the overall effectiveness of an intervention. Please complete this one form for I estimate that the form will take about 15 minutes. Please retum the completed form to Mrs. Jones in this envelope. Thank you very much for your help!

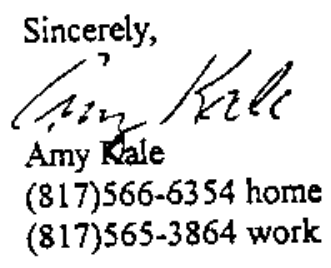


APPENDIX D

CHILD DATA SHEET 
CHIED DATA SHEET

Child's Nome:

Last First M.Intial

Gender: Male___ Female___ Date of Birth:

Ethnicity: African American __Asian_Bi-racial_Caucasion_Hispanic/Latin _

Native American_Other(explain)

Child's primory longuage:

Language spoken at home:

Grade Level (now):

Retained: No Yes If yes, what grade School Child attends:

Teacher(s): SchoolCounselor:

Is your child receiving special educational or other services? If so explain

Mother's Name: $\begin{aligned} & \text { Last } \\ & \text { City }\end{aligned}$
Home Phone:
Work Phone:


Date of Birth Occupation

Last year of education completed:

\section{GENERAL INFORMATION}

Chitd's Primory Household: Mother only _ Father only _ Natural parents__ Natural mother and isep-izter___ Natural father and step-mother Blended farnily (both spouses with childres) Acoptive parents_ Relatives__ Foster tamily Institution Other

tist jy fousehold vour child's current fomily, beginning with the oldest member and include the shild: Primary Bousebold

Viame Age Gender Relationship so the child (inciude "step", "haif", etc.)

Secoud Househoid (If applicable)

vame

Age Gender

Reiationship to the child (ircluce "step", "hair", etc.)

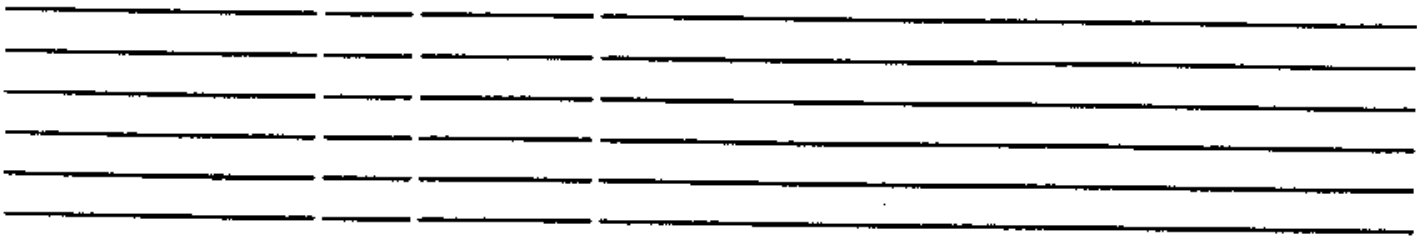

Currently imolved in a custody dispute: no_ yes__(If yes, explain)

If Jivorced. strcle the mumber which best describes your relationship with your ex-spouse. Hostile Frustratiog 1 3 Friendly $+\quad 5$ 
Date of LAST complete physical:

Physical Disability: yes_ no _ (if yes, explain Chronic Iliness: yes_ no__ (if yes, explain

Check the following items for a diagnosis or medication your child has received:

Diagrosis Current Past Date of Diagnosis Name of medication dosage

Depression

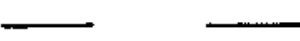

ADHD

Hyperacive

ADHD

Inangorive

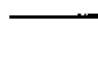

Conguct

Disorder

Leming

Disabrlity

Anxiety

Vervousness

Pasic Artack

Manic-Depression

(Bipolar)

Senizophrenia

Moodinger
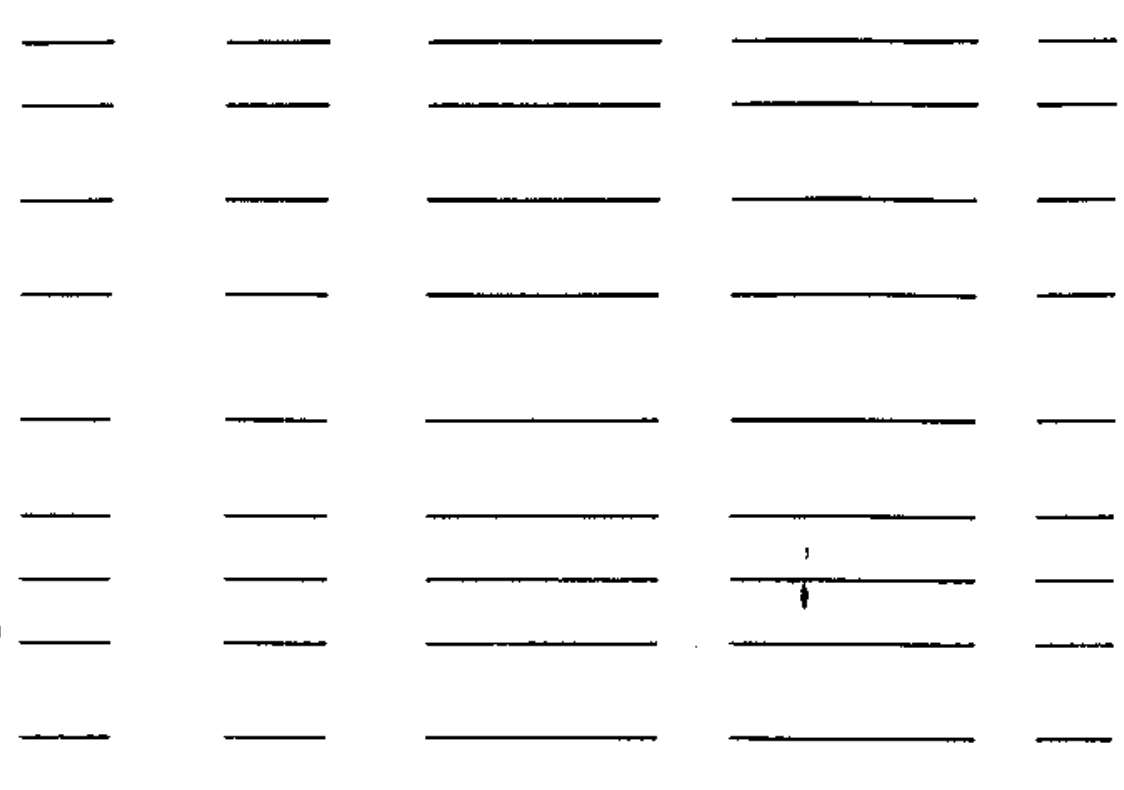

Tis

Insomial

Sleeplessness

Obsessive

Compulsive

Couvulsions

Bedrectiong

Arshme

Other
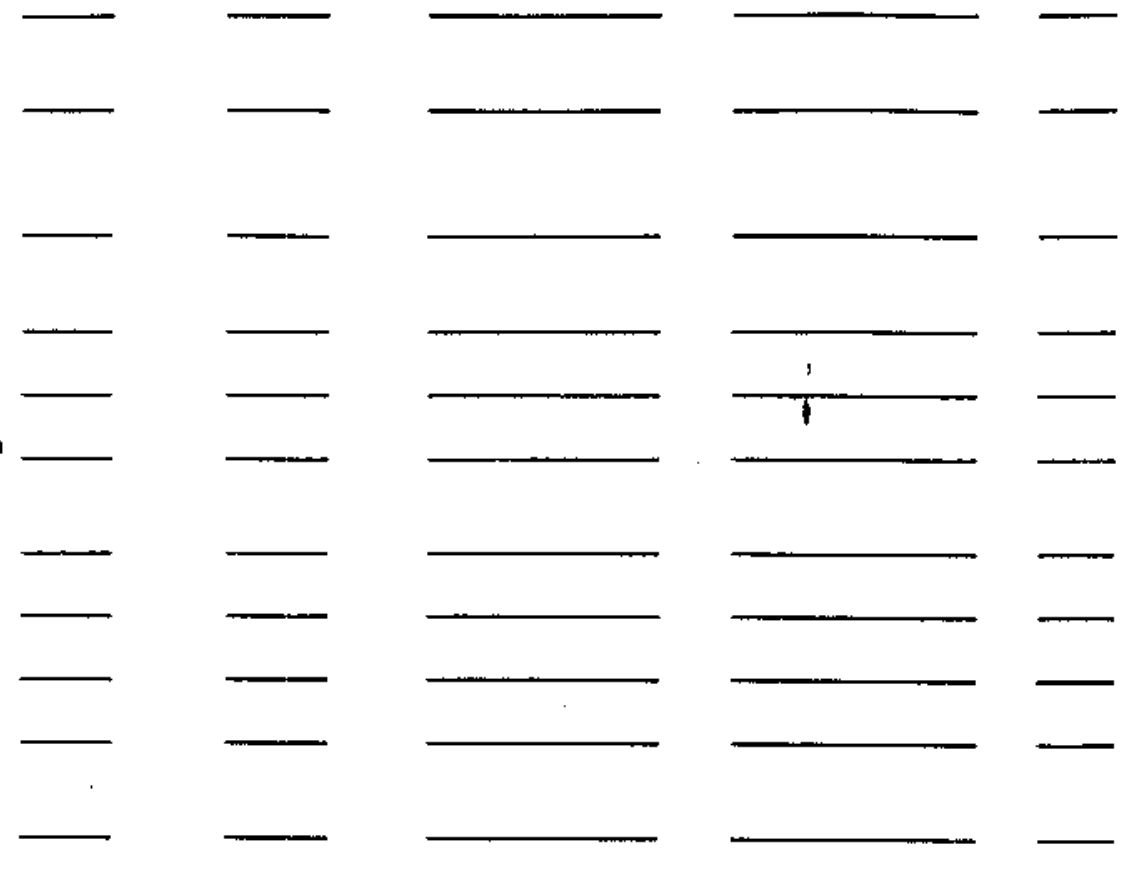

If your child has been diagnosed, who gove the diagnosis? Pediatrician Other

Psychiatrist School

What other medication is your child curenty taking?

Dosage

Child Data Sheer $6 / 96$ 

Fanily Problem History (Plecse check up to 10 items that corrently apply you child. Circle the item
that vou see as the most significant issue in your child's life)

Bed weating and related problems soiling

tbuse (physical exorional, sexual)

Chitd's disruptive behavior (aggression

Child's inappropriare behavior

ang ous, attention deficit, hyperactivity, annoying, iepetetitious, etc.)

Drug or aleohol use (both abuse, neglect or other tratrmatic experience)

Eating problem (purging legal and illegal drugs)

Feeling anxious (nerous, clingy, overeating, hoarding, severely restristing diet)

Feeling angy or intable

- Feeling guilty or shamefis

_Feeling sadress depression or suicidal urges celared to arief

- Gang zelated concerns fexplan sticidal urges VOT_ciated in sciej

Heald concern

- Healdt concerns (physical sompiainis and'or medical problems)

—Laming/Acadenic difficulties

- Personal Growth (no sectifis proble

Parent-Child telationstip (discipline adog)

- Famtly or Step-famly telascipline, adoption, single parent, etc.)

- Non. Ganty retarionship (roomship (not parent-child or purtner)

- Sexual concerns (excessuve matertes, elassmatcs, lachers playmales, etc.)

Sexual identity concera

- Sleep problem (nigntmares, tight-terror, slesping too muct or too linle. etc.)

- Utusual expertences tloss di periods of time. sensing unreal thrngs. tac.)

- Voseconal coneems

- Other iexplain

* Remember to circle the nost significont issue.

When did you first become concemed about your child and this issue?

How hove you attemered before now ro deal with your child's current issue?

Other Treafment; :ow chitd has recerved: Nore

Hospitalization

$$
\text { P!ay Taerapy }
$$
Other (explain) Individual counseling Family zounseling.

Anyhing slse you think we need to brow:

What does the coumselor most need to brow in order to be helpful today?

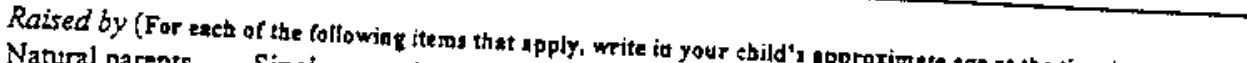
Natural parents _. Single natural parent Grandparents step-parent _ Foster parents_ Institution_ Relatives_. Adoptive parent(s)_ Natural and

Stressors in the Family: Parents fighting frequently

Family member's disability or major accident or illness Moved a lot__ Eamily member sbsent (explain) Family member suicide (explain)

Parents divoreed Financial problems Chronic illness of family member Ocher (explain)

) Death of significant person

Abused (check anl that apply): Physically Emotionally Sexuaily

Child Data Sheet 696 
Neglected (chect at thar appiy): Physicaily___ Emotionally School Problems (check il that apply); Academic problems__ Severely teased _ Discipline
probiens_ Unpopular_ Other (explain) Other (explain)

Early Language/Speech Problems: (explain)

Emotional Concems: Emotional problems__ Suicide attempts__ Other (explain

Behovior Probiems (check all that wply): Misbehaved a lot__ Trouble witt the law__ Invoived with the juverile systen_ _. R.n away Impuisive __ Alcohol and/or drug use__ Hyperactive Asention problems _ Acsident-prone_Frequent arguments _ Taken advantage of - Temper vutoursts_ Slapping, hiring, shoving__ Loner__ Other

Phisicat Problems (check al that upply): Major illness__ Major accident itiness__ Hospituization _ Developmental delay(s)__ Sleep problem Disability Chronic overeating or andereating Neurological proplears/exam Other

Trasma Stressor on Child (check al] that apply): Child separated from parent (how long and when) Deach of a significant person. Death of a pet Increserated bamily mencer _ Sexual Assault_ Victim of trama (unusual, tertifying

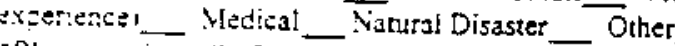

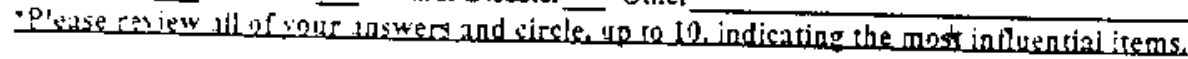

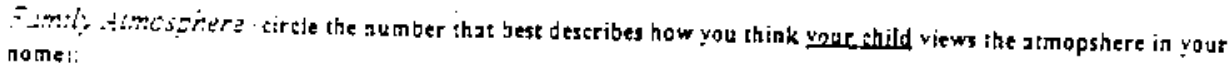

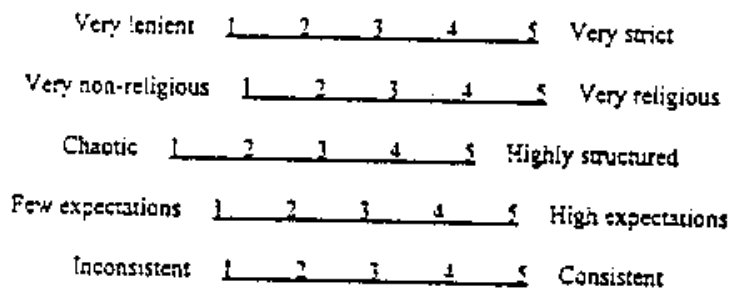

Fimity Support Sistem 'such ss sharch, friends, relarives, school):

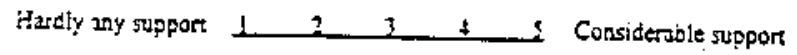

Child's ise of Computer, $V C R$ and Television (circle the aumber of thoun that deat describes use):

Computer (circle approximate hours spent each weet)

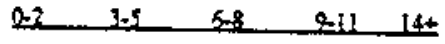

TVNCR (circle spproximenalte hours spent each weecix)

0.2 . $3-5 \quad 6-8 \quad 0.11 \quad 14$ 


\section{APPENDIXE LETTER OF PERMISSION TO USE PORTER PARENTAL ACCEPTANCE SCALE}


BLAINE R. PORTER

January 21,1997

Amy Kale

900 Londonderry Lane Apt. 240

Denton, TX 76205

Dear Ms Kale:

I was pleased to leam in our telephone conversation today of your interest in using my Parental Acceptance Scale. I hereby grant you permission to use it. For your convenience I am enclosing a copy of the latest revision, Instuctions'for Administering it and a Scoring Key.

If it proves to be of use to you in your research, I will appreciate your sending me a copy of the results of your study.

Best wishes to you in your research project.

Sincerely,

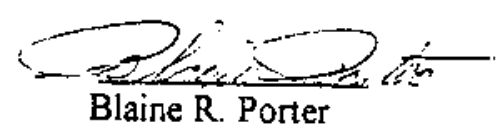

BRPYms

Enclosures 


\section{APPENDIX F \\ PORTER PARENTAL ACCEPTANCE SCALE}




\section{PORTER PARENTAL ACCEPTANCE SCALE}

We are trying to learn more about parent-child relationships. Please assist us by filling out this questionnaire as frankly and as carefully as possible. Your answers will be absolutely confidential. You have been asked to focus on only one child during this training...please think only of that child as you answer these questions. Please answer afl questions. If you cannot give an exact answer, answer the best you can.

\section{INFORMATION ABOUT YOUR CHILD}

Many parents say that their feelings of affection toward or for their child varies with the child's behavior and with circumstances. Please read each item carefully and place a check in the column which most nearly describes the degree of feeling of affection which you have for your child in that situation.

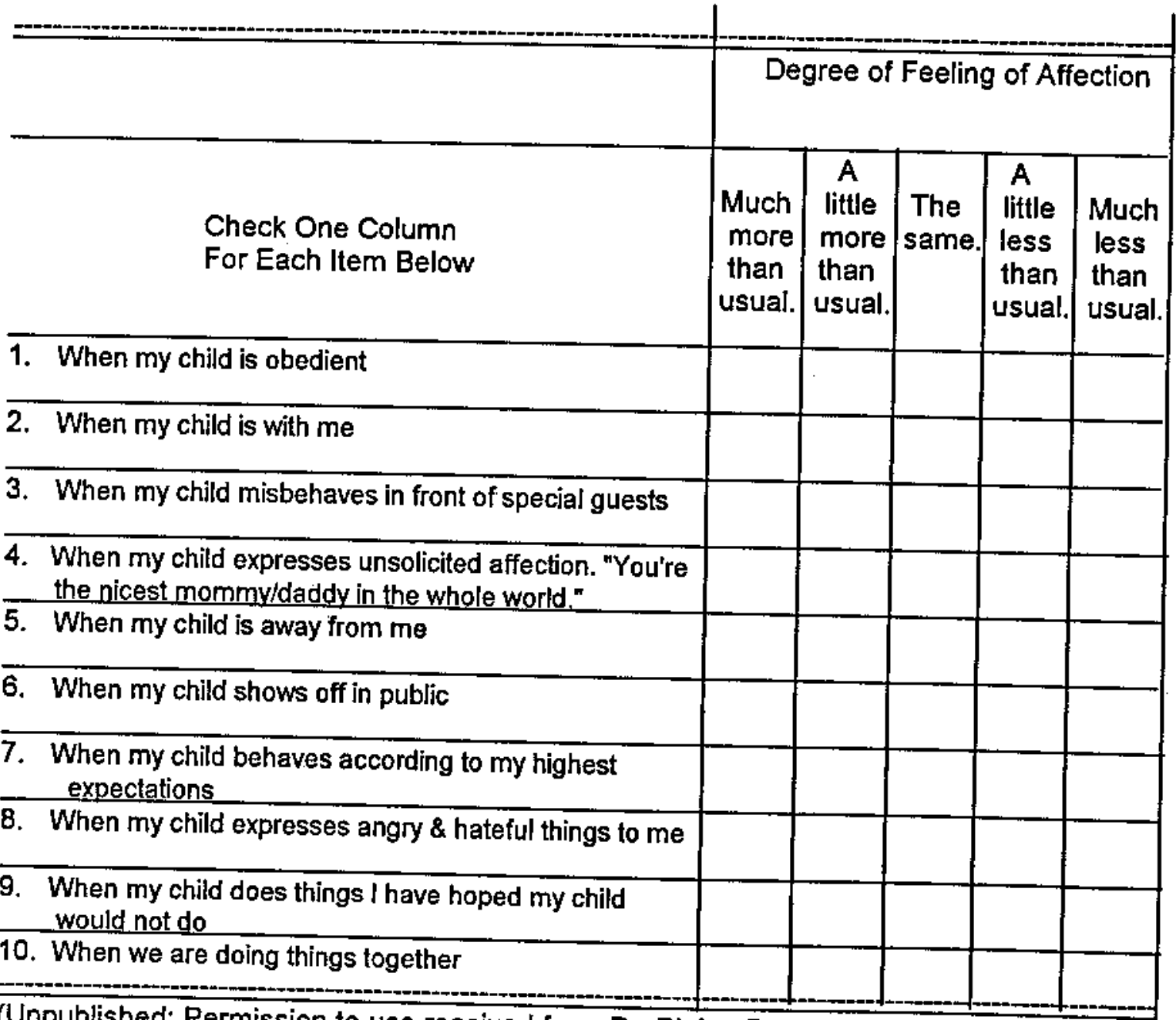
(Unpublished: Permission to use received from Dr. Blaine Porter, Brigham Young
University.) 
Listed below are several statements describing things which children do and say. Following each statement are five responses which suggest ways of feeling or courses of action.

Read each statement carefully and then place a circle around the number in front of the one response which most nearly describes the feeling you usually have or the course of action you most generally take when your. child says or does these things.

It is possible that you may find a few statements which describe a type of behavior which you have not yet experienced with your child. In such cases, mark the response which most nearly describes how you think you would feel or what you think you would do.

Be sure that you answer every statement and mark only one response for each statement

11. When my child is shouting and dancing with excitement at a time when I want
peace and quiet, I:
a. feel annoyed.
b. want to know more about what excites my child.
c. feel like punishing my child.
d. feel that I will be glad when my child is past this stage.
e. feel like telling my child to stop.

12. When my child misbehaves while others in the group are behaving well, I:
a. see to it that my child behaves as the others.
b. tell my child it is important to behave well when in a group.
c. let my child alone if the others are not disturbed by the behavior.
d. ask my child to suggest an alternate behavior.
d. ask my child to suggest an alternate behavior.
e. help my child find an alternate behavior to enjoy while not disturbing
the group.

13. When my child is unable to do a thing which I think is important for him/her, l:
a. want to help my child find success in other things.
b. feel disappointed in my child.
c. wish my child could do it.
d. realize that my child can not do everything.
e. want to know more about the things my child can do.

14. When my child seems to be more fond of someone else (teacher, friend,
relative) than me, l:
a. realize that my child is growing up.
b. feel resentful.
d. feel that my child doesn't appreciate what I have done for him/her.
e. wish my child liked me more. 
15. When my child is faced with two or more choices and has to choose only one,

a. tell my child which choice to make and why.

b. think it through with my child.

c. point out the advantages and disadvantages of each, but let my child

d. tell my child that I am sure he/she can make a wise choice and help

e. make the decision for my child.

16. When my child makes decisions without consulting me, l:

a. punish my child for not consulting me.

b. encourage my child to make many of his/her own decisions.

c. allow my child to make many of his/her own decisions.

d. suggest that we talk it over before he/she makes the decision.

e. tell my child he/she must consult me first before making a decision.

17. When my child kicks, hits, or knocks his/her things about, I:
a. feel like telling my child to stop.
b. feel like punishing him/her.
c. am pleased that my child feels free to express himself/herself.
d. feel that I will be glad when my child is past this stage. 18. When my child is not interested in some of the usual activities of his/her age
group, l:

a. realize that each child is different.

b. wish my child were interested in the same activities.

c. feel disappointed in my child.

d. want to help my child find ways to make the most of his/her interests.

e. want to know more about the activities in which my child is interested.

19. When my child acts silly and giggly, l:
a. tell my child I know how he/she feels.
b. pay no attention to him/her.
c. tell my child he/she shouldn't act that way.
d. make my child quit.
e. tell my child it is all right to feel that way, but help him/her find other
ways of expression.

20. When my child prefers to do things with his/her friends rather than with the
family, l:
a. encourage my child to do things with his/her friends.
b. accept this as part of his/her growing up.
d. plan special activities so that my child will want to be with the family.
e. make my child stay with the family. 
21. When my child disagrees with me about something which I think is important,

a. feel like punishing him/her.

b. am pleased that my child feels free to express his/her thoughts and feelings.

c. feel like persuading my child that my way is best.

d. realize my child has ideas of his/her own.

e. feel annoyed.

22. When my child misbehaves while others in his/her group are behaving well, I:

a. realize that my child does not always behave as others in his/her

b. group.

b. Teel embarrassed.

c. want to help my child find the best ways to express his/her feelings.

d. wish my child would behave like the others.

e. want to know more about his/her feelings.

23. When my child is shouting and dancing with excitement at a time when I want peace and quiet, l:
a. give my child something quiet to do.
b. tell my child that I wish he/she would stop.
c. make my child be quiet.
d. let my child tell me about what is so exciting.
e. send my child somewhere else. 24 . When my child seems to be more fond of someone else (teacher, friend,
relative) than me, l:
a. try to minimize my child's association with that person.
b. let my child have such associations when I think he/she is ready for
c. do some special things for my child to remind him/her of how nice I
d. point out the weaknesses and faults of the other person(s).
e. encourage my child to create and maintain such associations.

25. When my child says angry and hateful things about me to my face, I:
a. feel annoyed.
b. feel that I will be glad when my child is past this stage.
c. am pleased that my child feels free to express himself/herself.
d. feel like punishing my child.
e. feel like telling my child not to talk that way to me.

26. When my child shows deep interest in something I don't think is important, $\mathrm{l}$ :
a. realize my child has interests of his/her own.
c. want to help my child find ways to make the most of this interest.
d. want to know more about my child's interests.
e. wish my child were more interested in the things I think are important
for him/her. 
27. When my child is unable to do some things as well as others in his/her group,
l:

a. tell my child he/she must try to do as well as the others.

b. encourage him/her to keep trying.

c. tell my child that no one can do everything well.

d. call attention to the things he/she does well.

e. help my child make the most of the activities which he/she can do well.

28. When my child wants to do something which I am sure will lead to disappointment for him/her, l:

a. occasionally let my child carry such an activity to its conclusion.
b. don't let my child do it.

c. advise my child not to do it.

d. help my child with it in order to ease the disappointment.

e. point out what is likely to happen.

29. When my child acts silly and giggly, I:

a. feel that I will be glad when he/she is past this stage.

b. am pleased that my child feels free to express himself/herself.

c. feel like punishing my child.

d. feel like telling him/her to stop.

30. When my child is faced with two or more choices and has to choose only one,

a. feel that 1 should tell my child which choice to make and why.

b. feel that I should point out the advantages and disadvantages of each.

c. hope that I have prepared him/her to choose wisely.

d. want to encourage my child to make his/her own choices.

e. want to make the decision for my child.

31. When my child is unable to do something which I think is important for him/her,
I:

a. tell my child he/she must do better.

b. help my child make the most of the things which he/she can do.

c. ask my child to tell me more about the things which he/she can do.

d. tell my child that no one can do everything.

e. encourage him/her to keep trying.

32. When my child disagrees with me about something which I think is important,
I:

a. tell my child he/she should not disagree with me.

b. make my child quit.

c. listen to my child's side of the issue and change my mind if that seems

d. tell my child maybe we can do it his/her way another time.

e. explain that I am doing what is best for him/her. 
33. When my child is unable to do some things as well as others in his/her group, l:

a. realize that my child can't do as well as others in everything.

b. wish that my child could do as well.

c. feel embarrassed.

d. want to help my child find success in the things he/she can do well.

e. want to know more about the things my child can do well.

34. When my child makes decisions without consulting me, I:

a. hope that I have prepared my child adequately to make his/her

decisions.

b. wish that my child would consult me.

c. feel disturbed.

d. want to restrict his/her freedom.

e. am pleased to see that as my child grows, I am needed less.

35. When my child says angry and hateful things about me to my face, 1 :

a. tell my child it is all right to feel that way, but help him/her find other

b. tell my child I know how he/she feels.

c. pay no attention to him/her.

d. tell my child he/she shouldn't say such things to me.

e. make my child quit.

36. When my child kicks, hits, and knocks his/her things about, I:

a. make my child quit.

b. tell my child it's alright to feel that way, but help him/her find other ways of expressing him/herself.

c. tell my child he/she shouldn't do such things.

d. tell my child I know how helshe feels.

e. pay no attention to him/her.

37. When my child prefers to do things with friends rather than with the family, l:

a. wish my child would spend more time with us.

b. feel resentful.

c. am pleased to see my child's interests widening to other people.
d. feel my child doesn't appreciate us.

e. realize that he/she is growing up.

38. When my child wants to do something which I am sure will lead to
disappointment, l:

a. hope that I have prepared him/her to meet disappointment.

b. wish that my child did not have to experience unpleasant events.

c. want to keep my child from doing it.

d. realize that occasionally such an experience will be good for him/her.

e. want to postpone these experiences. 
39. When my child is not interested in some of the usual activities of his/her age group, l:

a. help my child realize that it's important to be interested in the same things as others in the group.

b. call attention to the activities in which he/she is interested.

c. tell my child it is all right not to be interested in the same things as others in his/her group.

d. see to it that my child does the same things as others in his/her group.

e. help my child find ways of making the most of his/her interests.

40. When my child shows a deep interest in something I don't think is important,

a. let my child go ahead this interest.

b. ask my child to tell me more about this interest.

c. help my child find ways to make the most of this interest.

d. do everything I can to discourage my child's interest in it.

e. try to interest him/her in more worthwhile things. 


\section{APPENDIX G}

FILIAL THERAPY TRAINING SESSION OUTLINES AND HANDOUTS 


\section{FILIAL SESSION \#1}

(Garry L. Landreth, 1983)

I. Introduce self, welcome group, give name tags and booklets to all members.

Il. Overview of Filial Training:

Play is the child's language.

Based on actions, not words.

Way of preventing problems since adults become aware of child's needs.

"In ten weeks, you are going to be different, and your relationship with your child will be different"

Techniques from play therapy will: Return control to you.

Provide closer, happier times with your child.

III. Group Introductions:

Give key to your child's inner world.

Describe entire family - help pick child of focus.

Tell concerns about this child (take notes).

Make generalizing comments to other parents..

"Anyone else felt angry with their child this weekr

IV. Provide Basic Agenda:

One-half hour play sessions.

Everyone will be video-taped here at least once for replay.

(Bring your own tape to keep.)

We will see demonstrations before starting.

Patience is important in learning a new language.

V. Show video tape of "Children's Emotions."

VI. Reflective listening: A way of following, rather than leading.

Don't ask questions.

Reflect behaviors, patterns and feelings.

Responses say:

I am here; I hear you.

I understand.

I care.
Not:

I always agree.

I must make you happy.

I will solve your problems.

Keep focus on the positive.

RULE OF THUMB: You can't give away what you do not possess. As significant care givers we may be coming to the sessions deeply aware of our
failures. Yet we can't effectively enter this process by being impatient and unaccepting
toward ourselves while trying to extend pation toward ourselves while trying to extend patience and acceptance to a child.

Homework:

(1) Notice some physical characteristic about your child you haven't seen before.

(2) Practice reflective listening this week (hand out 4 faces sheet). 
NOTES: Filial Session\#1

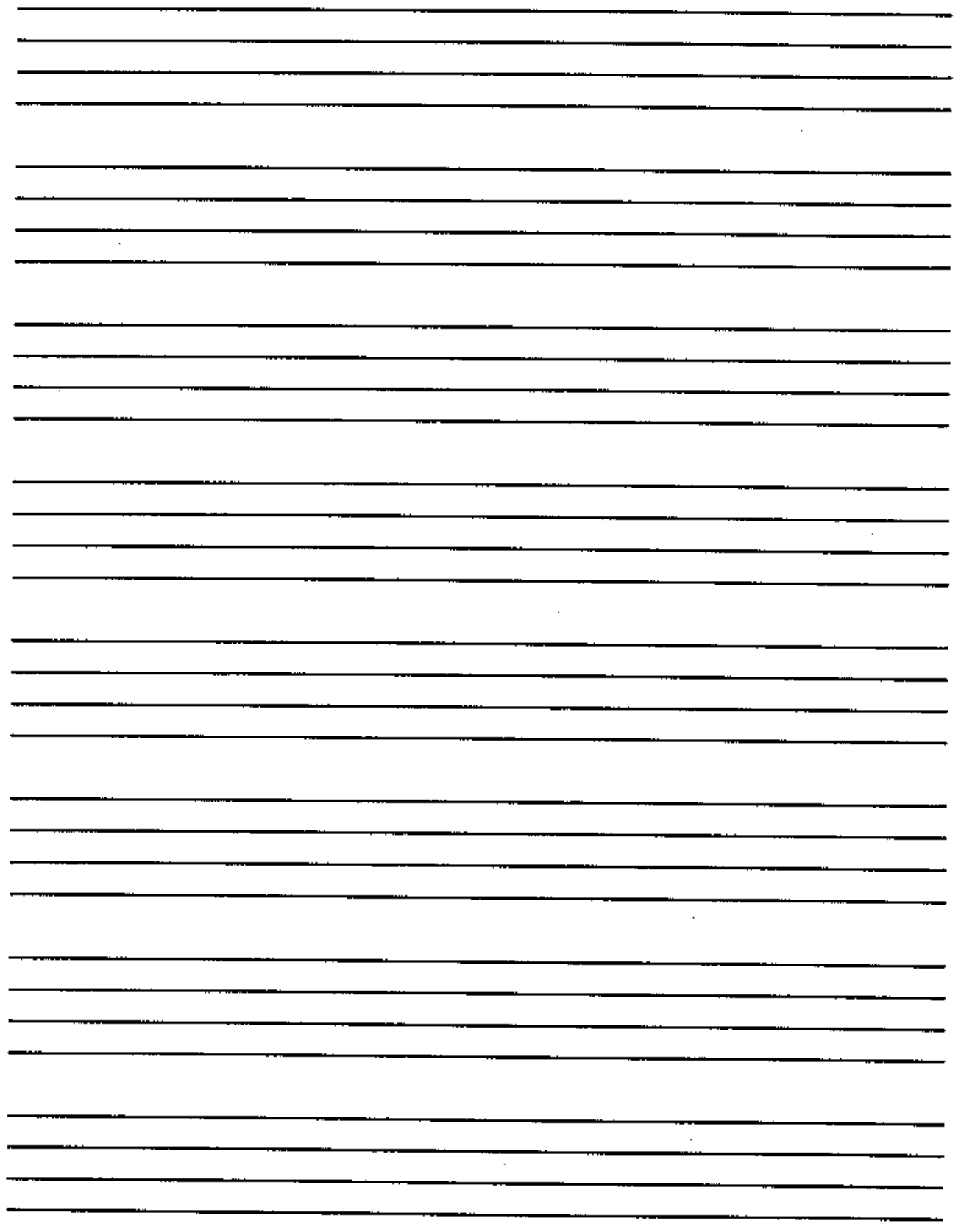




\section{THE FOUR BASIC FEELINGS}

(Garry L. Landreth, 1983)

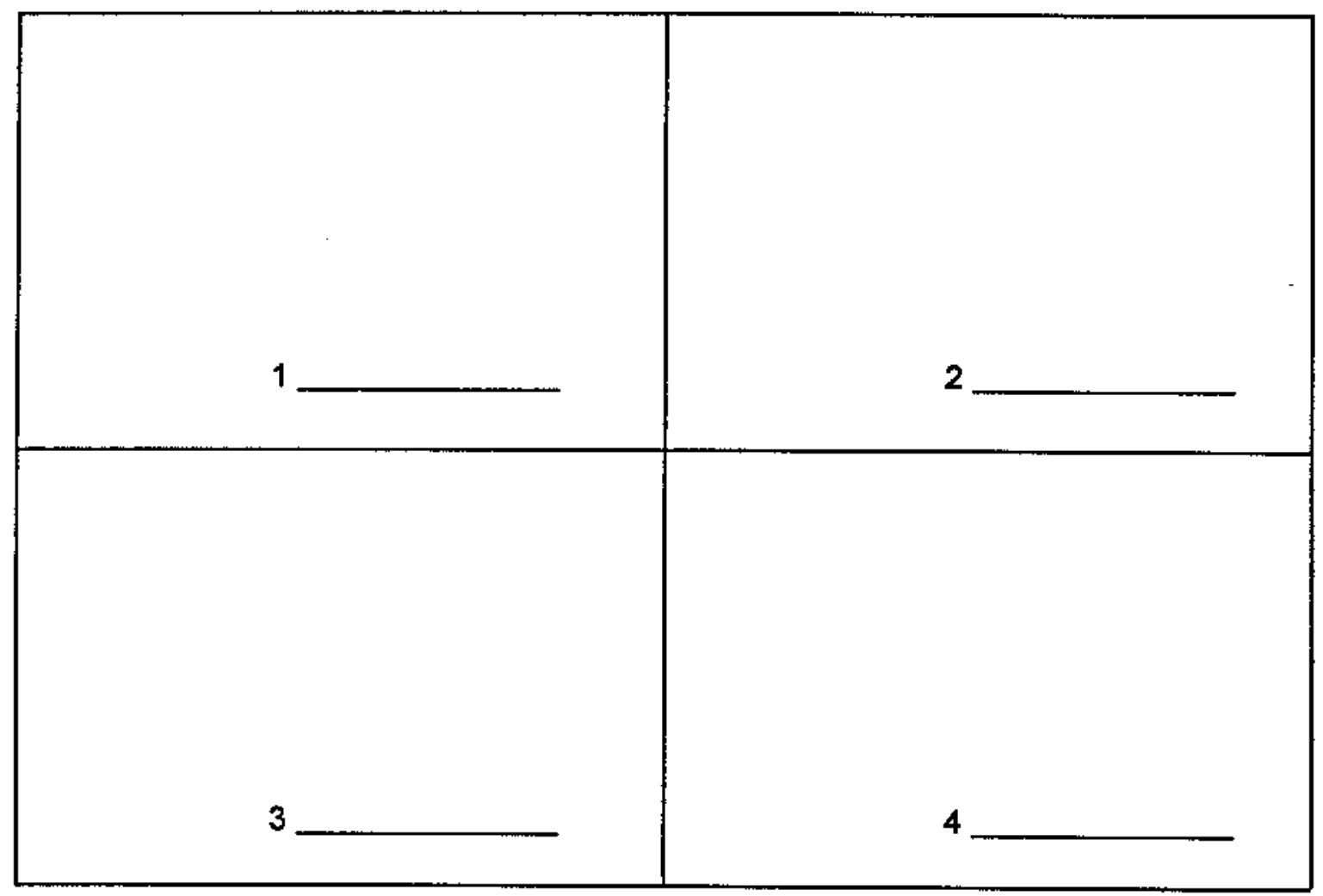

Reflective responses this week.

1.

2.

3.

4.

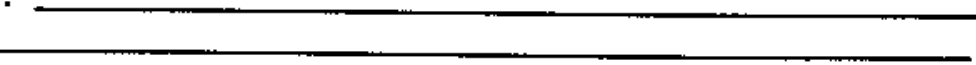




\section{FILIAL SESSJON \#2}

(Garry L. Landreth, 1983)

I. Review homework:

(1) Physical Characteristic

(2) 4 Faces Sheet

II. Handout: "Filial Therapy Group"

Go over entire sheet, especially list of toys. (Demonstration Box.)

The "how to" of play sessions.

III. Show video tape of session or do live demonstration.

IV. Have participants pair off and role play to practice reflective responding.

RULE OF THUMB: When a child is drowning, don't try to teach the child to swim.

If a child is feeling upset, that is not the moment to impart a rule or value.

\section{Homework:}

(1) "Facilitating Reflective Communication" handout.

(2) Pick spot and time for sessions - report back next week. 
FILIAL THERAPY GROUP

Session \#2 Handout A

(Garry L. Landreth, 1983)

Basic Principles of the Play Sessions

(1) The child should be completely free to determine how the child will use the time. The child leads and the parent follows without making suggestions or asking questions.

(2) The adult's major task is to empathize with the child, to understand the intent of the child's actions, and the child's thoughts and feelings.

(3) The parent's next fask is to communicate this understanding to the child by appropriate comments, particularly, whenever possible, by verbalizing the feelings that the child is actively experiencing.

(4) The parent is to be clear and firm about the few "limits" that are placed on the child. Limits set are on time, not breaking specified toys, and not physically hurting the adult.

Goals of the Play Sessions

(1) To help the child change perceptions of the adult's feelings, attitudes, and behavior.

(2) To allow the child - through the medium of play - to communicate thought, needs, and feelings to the adult.

(3) To help the child develop more positive feelings of self-respect, self-worth, confidence.

\section{REMINDER}

These play sessions and the techniques you use are relatively meaningless if they are applied mechanically and not as an attempt to be genuinely empathic and to truly understand your child.

Toys for the Play Sessions

Creative: Play Doh, crayons ( 8 colors), paper, blunt scissors,

Nurturing: nursing bottle (plastic), doll, small blanket, tea set for two, doctor kit, Aggressive: rubber knife, dart gun, toy soldiers (10-15), punching bag, 5 ' rope, toy snake

Dramatic: family of small dolls, doll house furniture, Lone Ranger type mask, hand

Other: puppet, plastic animals (2 domestic, 2 wild)

Other: $\quad$ small plastic car, Tinkertoys, ball (soft sponge type), bowling pins \& ball

\section{Place for the Play Sessions}

Whatever room you feel offers the fewest distractions to the child and the greatest freedom from worry about breaking things or making a mess. Set aside a regular time in advance. This time is to be undisturbed -- no phone calls or interruptions by other children. You may wish to explain to your child that you are having these sessions because you are interested in learning how to play with the child in a different, "special" way than you usually do.

\section{Process}

Let the child use the bathroom prior to the play sessions. Tell the child, "we will have thirty minutes of special play time and you may choose to play with the toys in many of the ways you would like." Let the child lead from this point. Play actively with the child if the child requests your participation. Set limits only behaviors that make you feel uncomfortable. Track the child's behavior and feelings verbally. Do not identify toys by their normal names; call them "it", "that", etc. Give the child a five minute advance notice before terminating the session. Do not exceed the time limit by more than two or three minutes. 
FACILITATING REFLECTIVE COMMUNICATION

Session \#2 Handout B

(Garry L. Landreth, 1983)

What response would you make to the following situations if you were practicing reflecting the child's feeling:

1. Joe: (With wrinkled brow, red face, and tears in his eyes) "We lost. That team didn't play fair!"

Adult:

2. Jill: (Enters with C- test paper in hand) "I tried so hard, but it didn't do any good."

Adult:

3. Janet: (Rummaging through her drawer wildly, looking for a particular sweater she wanted to wear to the party she had been looking forward to for a long time) "I can never find anything I want." (Begins to cry)

Adult:

4. John: (Undressing Barbie doll) "Wow!" Look at her butt!"

Adult:

5. Carol: (Looking through the dooway to a dark room) "What's in there? Will you come with me?"

Adult:

6. Charlie: (Showing you his torn, smudged painting from school) "Look! Isn't it neat! My teacher said I was a good artist!"

Adult: 


\section{FILIAL SESSION \#3}

(Garry L. Landreth, 1983)

1. Review homework:

(1) "Facilitating Reflective Communication" Handout

(2) Time and Place for Play Sessions

NAME TIME PLACE

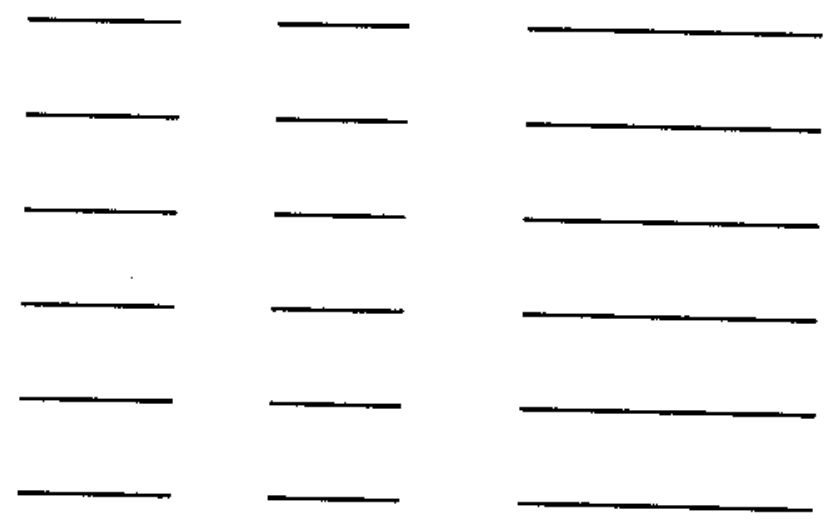

(3) Toys

II. Handout in Class: "Basic Rules for Filial Therapy".

Use to review rules for play sessions.

Basic Limits: Child's name

Reflect feeling ... "I know you'd like to shoot the gun at me...

Set limit ... but, I'm not for shooting.

Alternative... You can choose to shoot at that (point at something acceptable)."

III. Demonstration

IV. Arrange for a parent to do video-taping during the week.

First Volunteer:

RULE OF THUMB: Be a thermostat, not a thermometer.

Reflecting feelings creates an environment that is comfortable and accepting, as opposed to merely reacting to feelings.

Homework:

(1) Begin play sessions at home this week. 


\section{BASIC RULES FOR FILIAL THERAPY}

Session \#3 Handout A

(Garry L. Landreth, 1983)

\section{Don't}

1. Don't criticize any behavior.

2. Don't praise the child.

3. Don't ask leading questions.

4. Don't allow interruptions of the session.

5. Don't give information or teach.

6. Don't preach

7. Don't initiate new behavior (These first 7 are taken from Guerney, 1972)

8. Don't be passive, quiet.

Do

1. Do set the stage.

2. Do let the child lead.

3. Do track behavior.

4. Do reflect the child's feelings.

5. Do set limits.

6. Do salute the child's power and effort.

7. Do join in the play as a follower.

8. Do be verbally active.

Check your responses to your children. Your responses should convey:

1. "You are not alone: I am here with you."

2. "I understand how you feel and I hear/see you."

3. "I care."

Your responses should not convey:

1. "I will solve your problems for you."

2. "I am responsible for making you happy."

3. "Because I understand you, that means I automatically agree w/you."

[Guerney, L. F. (1972). Play therapy:A training manual for parents. Mimeographed Report.] 
Session \#3 Handout B

\section{THE EIGHT BASIC PRINCIPLES \\ (of Non-Directive Play Therapy)}

Nirginia M. Axline, 1969)

1. The therapist must develop a warm, friendly relationship with the child, in which good rapport is established as soon as possible.

2. The therapist accepts the child exactly as the child is.

3. The therapist establishes a feeling of permissiveness in the relationship so that the child feels free to express feelings completely.

4. The therapist is alert to recognize the feelings the child is expressing and reflects those feelings back to the child in such a manner that the child gains insight into behavior.

5. The therapist maintains a deep respect for the child's ability to solve problems if given an opportunity to do so. The responsibility to make choices and to institute change is the child's.

6. The therapist does not attempt to direct the child's actions or conversation in any manner. The child leads the way; the therapist follows.

7. The therapist does not attempt to hurry the therapy along. It is a gradual process and is recognized as such by the therapist.

8. The therapist establishes only those limitations that are necessary to anchor the therapy to the world of reality and to make the child aware of the child's responsibility in the relationship.

[Axline, V. M. (1969). Play Therapy. New York: Ballantine Books. \{pp. 72-73\}] 
FILIAL SESSION \#4

(Garry L. Landreth, 1983)

I. Debriefing. How did the play sessions go?

(Be aware of the time - keep group process movingl)

II. As reporting is occurring, use their examples to illustrate rules of filial therapy. Also, focus on how they were able to reflect on their child's feelings.

III. Handout: "Two Techniques of Discipline that Work".

Go over importance of using this as first step in discipline process.

IV. Arrange for next parent to video tape.

Second Volunteer:

V. Show video tape from first volunteer.

RULE OF THUMB: Good things come in small packages.

We enter our child's world in little ways, not big ones.

We can't expect to be part of only the big events in our child's life.

Homework:

(1) Notice one intense feeling in yourself this week. 
TWO TECHNIQUES OF DISCIPLINE THAT WORK

Session \#4 Handout

(Garn L. Landreth, 1983)

1. Eirm limit-setting

A. Three steps:

(1) Recognize the feeling - "I know you'd really like to ..." ", or "I can tell you're really feeling....", etc.

(2) Set the limit - "... but you may not ____.", or "... but the cabinet door is not for kicking.", or ". . but the answer is no."

Provide an alternative - "You can ___ if you'd like.", or

"You can choose to

B. After three-step process, DON'T discuss: "I can tell you'd lie to discuss this some more, but ive already answered that question."

C. If you're not prepared to answer the question (want to talk it over with someone; want to get more information; want to think about it).

(1) "I can't answer that question now... (because ....)." "I'll let you know (specific time)."

(2) Nagging begins: "If you must have an answer now, the answer will have to be NO."

D. If the child asks the same question again: Calmly - "I've already answered that question." Variations:

(1) "Do you remember the answer I gave you a few minutes ago when you asked that same question?" (Child answers, "No, I don't remember.") "Go sit down in a quiet place and think and I know you'll remember."

(2) "I've answered that question once (twice), that's enough."

(3) If you think the child doesn't understand: "I've already answered that question. You must have some question about the answer."

E. If you're undecided and open to persuasion: "I don't know ... Let's sit down and discuss it."

2. Oreo Cookie Theory: Give the child a choice, providing acceptable choices commensurate with the child's ability to choose. 
FILIAL SESSION \#5

(Garry L. Landreth, 1983)

I. Debriefing, combined with report on one intense feeling they had. Focus on importance of awareness of themselves in the play sessions.

II. Handout: "When Setting Limits Doesn't Work"

III. Arrange next taping session.

Taping Session:

IV. Review video of play session.

RULE OF THUMB: The most important thing may not be what you do, but what you do after what you have done.

It's not whether we make mistakes, but how we handle our mistakes that counts.

Homework:

(1) Sandwich hugs - explain.

(2) Continue play sessions.

(3) Practice giving one choice. 
Session \#5 Handout

\section{WHEN "SETTING THE LIMIT" DOESN'T WORK...}

(Garry L. Landreth, 1983)

You have been careful several times to 1) reflect the child's feelings, 2) set clear, fair limits, and 3) give the child an alternate way to express feelings. Now the child continues to deliberately disobey. What do you do?

1. Look for natural causes for rebellion: Fatigue, sickness, hunger, extreme stress, abuse/neglect, etc. Take care of physical needs and crises before expecting cooperation.

2. Remain in control, respecting yourself and the child: You are not a failure if your child rebels, and your child is not bad. All kids need to "practice" rebelling.

3. Set reasonable consequences for disobedience: Let the child choose to obey or disobey, but set a reasonable consequence for disobedience. Example: "If you choose to watch TV instead of going to bed, then you choose to give up TV all day tomorrow."

4. Never tolerate violence: Physically restrain the child who becomes violent, without becoming aggressive yourself. Reflect the child's anger and loneliness. Provide compassionate control and alternatives.

5. If the child refuses to choose, you choose for the child: The child's refusal to choose is also a choice. Set the consequences. Example: "If you choose not to (choice $A \ldots$ or $B$ ), then you have chosen for me to pick the one that is most convenient for me."

6. ENFORCE THE CONSEQUENCES: "Don't draw your gun unless you intend to shoot." If you crumble under your child's anger or tears, you have abdicated your role as adult and lost your power. GET TOUGH: TRY AGAIN.

7. Recognize signs of depression: The chronically angry or rebellious child is in emotional trouble and may need professional help. Share your concerns with the child. Example: "John, l've noticed that you seem to be angry and unhappy most of the time. I love you, and I'm worried about you. We're going to get help so we can all be happier." 


\section{FILIAL SESSION \#6}

(Garry L. Landreth, 1983)

1. Debriefing on play sessions and giving one choice.

II. Handout: "Common Problems in Filial Therapy"

III. Arrange next taping session.

Taping Session:

RULE OF THUMB: Grant in fantasy what you can't grant in reality.

It's okay for the "baby brother" doll to be thrown out a window in play time.

\section{Homework:}

(1) Write a note to your child of focus (as well as other children in the family) for three weeks, pointing out a positive character quality you appreciate.

"I was just thinking about you and I think you are That is such an important quality, we're going to put this note up."

(2) Continue play sessions -- notice patterns of play that are showing up. 
COMMON PROBLEMS IN FILIAL THERAPY

Session \#6 Handout

(Garry L. Landreth, 1983)

1. Q: My child notices that I talk differently in the play sessions, and wants me to talk "normally". What should i do?

A:

2. Q: My child asks many questions during the play sessions and resents my not answering them. What should I do?

A:

3. Q: I'm bored. What's the value of this?

A:

4. Q: My child doesn't respond to my comments. How do I know I'm on target?

A:

5. Q: When is it okay for me to ask questions, and when is it not okay? A:

6. Q: My child hates the play sessions. Should I discontinue them? A:

7. Q: My child wants the play time to be longer. Should / extend the
session? A: 


\section{FILIALSESSION.\#7}

(Garry L. Landreth, 1983)

I. Debriefing on play sessions with focus on patterns.

II. Review reflective listening, setting limits, giving choices, etc.

III. Show video tape of session.

IV. Arrange next taping session.

Taping Session:

RULE OF THUMB: Praise the effort, not the product.

Homework:

(1) Notice the number of times during the week you touch your child.

(2) Continue play sessions. 


\section{FILIAL SESSION \#8}

(Garry L. Landreth, 1983)

I. Debriefing on play sessions and number of times they physically touched their child.

II. Show video tape of session.

III. Arrange next taping session.

Taping Session:

RULE OF THUMB: If you draw your gun, shoot.

Idle threats harm your relationship with your child.

Homework:

(1) Continue play sessions.

(2) Write down any unanswered questions and bring next time. 


\section{EILIAL SESSION \#9}

(Garry L. Landreth, 1983)

I. Debriefing on play sessions. Give time for questions on various topics.

II. Show video tape of session.

III. Arrange last taping session.

Taping Session:

IV. Mention filial follow-up meetings.

RULE OF THUMB: Don't answer questions that haven't been asked. Look behind the question for the deeper question.

Homework:

(1) Continue play sessions. 


\section{FILIAL SESSION \#10}

(Garry L. Landreth, 1983)

I. Briefly debrief.

II. Show last video taped session.

III. Handout: "Rules of Thumb and Other Things to Remember"

IV. Closing Procedures:

Focus on looking at differences in child and adult -- then and now. Encourage feedback within group on positive changes made.

(Praise them, they may be scared about leaving the safety of the groupl)

V. Emphasize continued meetings.

V. Encourage them to continue play sessions.

"If you stop now, the message is that you were playing with your child because you had to, not because you wanted to."

RULE OF THUMB: If you can't say it in 10 words or less, don't say it.

\section{Recommended Reading:}

1. How to Really Love Your Child, Campbell.

2. Between Parent and Child, Ginott.

3. Liberated Parents, Liberated Children, Faber \& Mazlish.

4. How to Talk So Kids Will Listen, \& Listen So Kids Will Talk, Faber \& Mazlish. 


\section{REFERENCES}

Abidin, R. (1983). Parenting stress index. Charlottesville, VA: Pediatric Psychology Press.

Achenbach, T. (1991). Child Behavior Checklist Computer Scored Profile, Parent and Teacher Forms. University of Vermont: Burlington, VT.

Achenbach, T. \& Edelbrock, C.(1981). Behavioral problems and competencies reported by parents of normal and disturbed children aged four through sixteen. Monographs of the Society for Research in Child Development, $\underline{46},(1$, Serial no. 18$)$.

Achenbach, T. \& Edelbrock, C. (1983). Manual for the Child Behavior Checklist and Revised Child Behavior Profile. Burlington, VT: University Associates in Psychiatry.

Adelman, H. S. \& Taylor, L. (1983). Enhansing motivation for overcoming learning and behavior problems. Journal of Learning Disabilities, 16, 384-392.

Amerikaner, M. J., \& Omizo, M. M. (1984). Family interaction and learning disabilities. Journal of Learning Disabilities, $17,540-543$.

Anderegg, M., Vergason, G., \& Smith M. (1992). A visual representation of the grief cycle for use by teachers with families of children with disabilities. Remedial and Special Education, 13 (2), 17-23.

Andronico, M., \& Blake, I. (1971). The application of filial therapy to young 
children with stuttering problems. Journal of Speech and Hearing Disorders, 36 (3), 377-381.

Andronico, M., \& Guemey, B. (1967). The potential application of filial therapy to the school situation. Journal of School Psychology, 6 (1), 2-7.

Appell, J., Williams, C., \& Fishell, K. (1964). Changes in attitudes of parents of refarded children effected through group counseling. American Journal of Mental Deficiency, 68, 104-108.

Ausubel, D. P., Balthazar, E. E., Rosenthal, I., Blackman, L. S., Schpoont, S. H., \&Welkowitz, J. (1954). Perceived parent attitudes as determinants of children's ego structure. Child Development, 25, 173-183.

Axline, V. M. (1969). Play therapy, New York: Ballentine Books.

Barkley, R. A., (1990). Attention-deficit hyperactivity disorder. A handbook for diagnosis and treatment. New York: Guilford Press.

Bavin-Hoffman, R. C. (1994). Filial therapy: A qualitative study of the parental perceptions of the process. Unpublished doctoral dissertation, Texas Woman's University, Denton.

Boersma, F., \& Chapman, J. (1979). Teachers' and mothers' academic achievement expectations for learning disabled children. Journal of School Psychology 31, 179-182.

Boll, L. (1972). Effects of filial therapy on maternal perceptions of their mentally retarded children's social behavior (Doctoral dissertation, The University of Oklahoma). Dissertation Abstracts International, 33, 6661A. 
Bratton, S. C. (1994). Filial therapy with single parents (Doctoral dissertation, University of North Texas, 1993). Dissertation Abstracts International. 54, (08), A2890.

Brendtro, L. K., \& Brokenleg, M. (1993). Beyond the curriculum of control. The Journal of Emotional \& Behavioral Problems, 1 (4), 5-11.

Burchinal, L., Hawkes, G., \& Gardner, B. (1957). The relationship between parental acceptance and adjustment of children. Child Development. 28, 67-77.

Census of population (1990 CP-2-1). Social and economic characteristics. United States, (1994). Washington DC: United States Department of Commerce, Economics and Statistics Administration, \& Bureau of Census.

Chapman, J. W. (1988). Cognitive-motivational characteristics and academic achievement of learning disabled children: A longitudinal study. Journal of Educational Psychology, 80,357-365.

Chapman, J. W., \& Boersma, F. J. (1979). Academic self-concept in elementary learning disabled children: A study with the Students' Perception of Ability Scale. Psychology in the schools, 16, 201-206.

Chau, I. (1996). Filial therapy with Chinese parents. Unpublished doctoral dissertation, University of North Texas, Denton, TX.

Chess, S., \& Thomas, A. (1987). Know your child. New York, Basic Books Inc.

Cooper, J. E., Holman, J., \& Braithwaite, V. A. (1983). Self-esteem and 
family cohesion: The child's perspective and adjustment. Journal of Marriage and the Family, 153-159.

Coopersmith, S. (1967). The antecedents of self-esteem. San Francisco:

W. H. Freeman.

Cox, W. H. (1970). Intrafamily comparison of loving-reject child-rearing practices. Chid Development. $91,437-448$.

Ditton, P.,Green, R. J., \& Singer, M. T. (1987). Communication

Deviancies: A comparison between parents of learning-disabled and normally achieving students. Family Process, 50, 75-87.

Durrant, J., Cunningham, C., \& Voelker, S. (1990). Academic, social, and general self-concepts of behavioral subgroups of learning disabled children. Journal of Educational Psychology, 82, 657-663.

Edelbrock, C., Greenbaum, R. \& Conover, N. (1985). Reliability and concurrent relations between the Teacher Version of the Child Behavior Profile and the Conners Revised Teacher Rating Scale. Journal of Abnormal Child Psychology . 13, 295-303.

Eiserman, W., Weber, C., \& McCoun, M. (1995). Parent and professional roles in early intervention: A longitudinal comparison of the effects of two intervention configurations. The Journal of Special Education. 29, 20-44.

Eisman, E. (1981). Sex-role characteristics of the parent, parental acceptance of the child and child self-concept (Doctoral dissertation, California School of Professional Psychology). Dissertation Abstracts International, 42. 
2026B.

Ellinwood, C. (1989). The young child in person-centered family therapy. Person-Centered Review, 4 (3), 256-262.

Faerstein, L. (1981). Stress and coping in families of learning disabled children: A literature review._Journal of Learning Disabilities. 14, 420-423.

Feagans, L. V.., Merriwether, A. M., \&Haldane, D. (1991). Goodness of fit in the home: Its relationship to school behavior and achievement in children with learning disabilities. Journal of Learning Disabilities. 24, 7, 413-419.

Gallagher, L. S. (1995). The impact of learning disabilities on families. Journal of Child Neurology, 10 (Suppl. 1), 112-113.

Ginott, H. G. (1965). Between parent and child. New York: McMillan Company.

Ginsberg, B. G. (1976). Parents as therapeutic agents: The usefulness of filial therapy in a community mental health center. The Psychoanalytic Study of the Child, 12, 250-262.

Ginsberg, B. G. (1989). Training parents as therapeutic agents with foster/adoptive children using the filial approach. In . E. Schaefer, \& J. M. Briesmeister (Eds.), Handbook of Parent Training: Parents as Co-Therapists for Children's Behavior Problems (pp. 442-478). New York: John Wiley \& Sons.

Glass, N. M. (1987). Parents as therapeutic agents: A study of the effect of filial therapy (Doctoral dissertation, University of North Texas, 1986). Dissertation Abstracts International, 47 (07), A2457. 
Glazer-Waldman, H. R. (1991). Filial therapy: CPR training for families with chronically ill children. Unpublished master's thesis, University of North Texas, Denton.

Glazer-Waldman, H. R., Zimmerman, J. E., Landreth, G. L., \& Norton, D. (1992). Filial therapy: An intervention for parents of children with chronic illness. International Journal of Play Therapy 1, 31-42.

Glover, G. J. (1996). Filial therapy with Native Americans on the Flathead Reservation. Unpublished doctoral dissertation, University of North Texas, Denton, TX.

Guerney, B. G., Jr. (1964). Filial therapy: Description and rationale. Journal of Consulting Psychology, 28 (4), 304-310.

Guerney, B. J., Jr. (Ed.). (1969). Psychotherapeutic agents: New roles for nonprofessionals, parents, and teachers. New York: Holt, Rinehart, and Winston.

Guerney, B. G., Jr. (1982). Filial therapy: Description and rationale. In G. L. Landreth (Ed.), Play therapy dynamics of the process of counseling with children (pp. 342-353). Springfield, IL: Charles C. Thomas.

Guerney, B., Coufal, J., \& Vogelsong, E. (1976). Filial therapy used as a treatment method for disturbed children. Evaluation, 3, 34-35.

Guerney, B. G., Jr., \& Flumen, A. (1970). Teachers as psychotherapeutic agents for withdrawn children. Journal of School Psychology, 8 (2), 107-113.

Guerney, B. G., Jr., Guerney, L. F., \& Andronico, M. P. (1966, March). 
Filial therapy. Yale Scientific Magazine.40 6-14.

Guerney, B. G., Jr., Guerney, L. F., \& Stover, L. (1972). Facilitative therapist attitudes in training parents as psychotherapeutic agents. The Family Coordinator, 21 (3), 275-278.

Guerney, B. G., Jr., \& Stover, L. (1971). Eilial therapy: Final report on MH 18254-01. Unpublished manuscript: The Pennsylvania State University at College Station.

Guerney, B. G., Jr., Stover, L., \& DeMerritt, S. (1968). A measurement of empathy for parent-child interaction. Journal of Genetic Psychology, 112, 49-55.

Guerney, L. F. (1972). Play therapy: A training manual for parents. Unpublished manuscript, The Pennsylvania State University at State College.

Guerney, L. (1976). Foster parent training project final report. Part II: Description and evaluation of the foster parent skills training program for parents for agency personnel. State College, PA: The Pennsylvania State University.

Guerney, L. F. (1983). Play therapy with learning disabled children. In C. Schaefer \& K. O'Connor (Eds.), Handbook of play therapy (pp. 419-435). New York: John Wiley \& Sons.

Guerney, L. F., \& Guerney, B. G., Jr. (1985). The relationship enhancement family of family therapies. In L. L'Abate, \& M. A. Milan (Eds.) Handbook of social skills training and research (pp. 506-525). Somerset, NY: John Wiley \& Sons.

Harris, Z. L. (1995). Eilial therapy with incarcerated mothers. Unpublished 
doctoral dissertation, University of North Texas, Denton.

Hornsby, L., \& Applebaum, A. (1978). Parents as primary therapists:

Filial therapy. In L. Arnold (Ed.), Helping parents help their children (pp. 126134). New York: Brunner \& Mazel.

Kaslow, F., \& Cooper, B. (1978). Family therapy with the learning disabled child and his/her family. Journal of Marriage and Family Counseling 4 , $41-49$.

Kezur, B. (1980). Mother-child communication patterns based on therapeutic principles (Doctoral dissertation, The Humanistic Psychology Institute). Dissertation Abstracts International, 41, 4671B.

Lahti, S. L. (1993). An ethnographic study of the filial therapy process (Doctoral dissertation, University of North Texas, 1992). Dissertation Abstracts International, 53 (08), A2691.

Landreth, G. L. (1983). Outline and handouts for the 10-week filial therapy training model. Unpublished manuscript, University of North Texas at Denton.

Landreth, G. L. (1991). Play therapy: The art of the relationship. Muncie, IN: Accelerated Development.

Latson, S. (1986). Effects of Adlerian parent education on parents' stress and perception of their learning disabled child's behavior. Unpublished doctoral dissertation, University of North Texas, Denton, TX.

Lebovitz, C. K. (1983). Filial therapy: Outcome and process (Doctoral dissertation, Texas Tech University, 1982). Dissertation Abstracts International. 
43 (12), B4152.

LeMaster, E. (1970). Parents in Modern America, Homewood, IL: Dorsey Press.

Lobaugh, F. A. (1992). Filial therapy with incarcerated parents. (Doctoral dissertation, University of North Texas, 1991). Dissertation Abstracts International, 53 (04), B2046.

Mercer, C. (1997). Students with Learning disabilities. Upper Saddle River, NJ: Merrill/Prentice Hall.

Moustakas, C. E. (1959). Psychotherapy with children, New York: Harper and Brothers.

Moustakas, C. E., \& Makowsky, G. (1952). Client-centered therapy with parents. Journal of Consulting Psychology, 16, 338-342.

Muehl, D., (1961). A manual for coders. Ann Arbor, Ml: University of Michigan.

O'Harra, D. M., \&Levy, J. M. (1984). Family adaptation to learning disability: A framework for understanding and treatment. Learning Disabilities, 3. 63-77.

Orvitz, E., \& Motta, R. W. (1992). Predictors of self-esteem: The roles of parent-child perceptions, achievement and class placement. Journal of Learning Disabilities, 25(1), 72-80.

Owen, F. W., Adams, P. A., Forrest, T., Stolz, L. M., \& Fisher, S. (1971). Learning disorders in children: Sibling studies. Monographs of the Society for 
Research in Child Development.36(4,Serial No. 144).

Oxman, L. K. (1972). The effectiveness of filial therapy: A controlled study (Doctoral dissertation, Rutgers University, The State University of New Jersey, 1972). Dissertation Abstracts International, 32. (11), B6656.

Packer, P. D. (1990). The initial process of filial therapy: A case study of a four year-old child and her parents (Doctoral dissertation, The Pennsylvania State University, 1990). Dissertation Abstracts International, 51 (06), A1903.

Payton, I. E. (1980). Filial therapy as a potential primary preventive process with children between the ages of four and ten (Doctoral dissertation, University of Northern Colorado, 1980). Dissertation Abstracts International, 41 (07), A2942.

Perkins, H. (1974). Human development and learning. Belmont, CA: Wadsworth.

Porter, B. (1954). Measurement of parental acceptance of children. Journal of Home Economics, 46 (3) 176-182.

Reynolds, M., Wang, M., \& Walberg, H. (1992). The knowledge bases for special and general education. Remedial and Special Education, 13 (5). 6-10, 33.

Rogers, C. (1951). Client-Centered Therapy. Cambridge: The Riverside Press.

Rogers, H., \& Saklofsky, D. H. (1985). Self-concepts, locus of control and performance expectations of learning disabled children. Journal of Learning 
Disabilities. 18, 273-278.

Rohner, E. C., (1980). Perceived parental acceptance-rejection and children's reported personality and behavioral dispositions: An intracultural test. Behavioral Science Research, 15, 81-88.

Rohner, E. C., Chaille, C., \& Rohner, R. P., (1980). Perceived parental acceptance-rejection and the development of children's locus of control. The Journal of Psychology, 104, 83-86.

Rohner, R. P., (1980). Worldwide tests of parental acceptance-rejection theory: An overview. Behavior Science Research, 15, 23-39.

Rohner, R. P., (1980). Handbook for the study of parental acceptance and rejection. Storrs, CN: The University of Connecticut.

Sensue, M. E. (1981). Filial therapy follow-up study: Effects on parental acceptance and child adjustment (Doctoral dissertation, The Pennsylvania State University, 1981). Dissertation Abstracts International, 42 (01), A148.

Stover, L., Guerney, B., \& O'Connell, M. (1971). Measurements of acceptance, allowing self-direction, involvement, and empathy in adult-child interaction. Journal of Psychology, 77, 261-269.

Strag, G. (1972). Comparative behavioral ratings of parents with severe mentally retarded, special learning disability, and normal children. Journal of Learning Disabilities, 5, 631-635.

Sywulak, A. E. (1977). The effect of filial therapy on parental acceptance and child adjustment. (Doctoral dissertation, Pennsylvania State University, 
1977). Dissertation Abstracts International, 38 (12), B6180.

Tew, K. (1997). The Efficacy of Filial Therapy With Families With

Chronically III Children. Unpublished doctoral dissertation, University of North Texas.

Tollison, P., Palmer, D.J., \& Stowe, M.L. (1987). Mothers' expectations, interactions, and achievement attributions for their learning disabled or normally achieving sons. The Journal of Special Education, 21 (3), 83-93.

Turnbull, A. P., \& Turnbull, H. R. Ill. (1990). Families, professionals. and exceptionality: A special partnership (2nd ed.). Upper Sadddle River, NJ: Merrill/Prentice Hall.

VanFleet, R. (1994). Filial therapy: Strengthening parent-child relationships through play. Sarasota, FI: Professional Resource Press.

Wall, L. (1979). Parents as play therapists: A comparison of three interventions into children's play (Doctoral dissertation, University of Northern Colorado). Dissertation Abstracts International, 40, 5597B.

Wikler, L. (1981). Chronic stresses of families of mentally retarded children. Family Relations, 30, 281-288.

Willner, S.K., \& Crane, R. (1979). A parental dilemma: The child with a marginal handicap. Social Casework, 60, 30-35.

Wright, L., Matlock, K., \& Matlock, D. (1985). Parents of handicapped children: Their self-ratings, life satisfactions and parental adequacy. The Exceptional Child. 32 (1), 37-40. 
Yuen, T. (1997). Filial Therapy with Immigrant Chinese Parents in

Canada. Unpublished doctoral dissertation, University of North Texas.

Zuckerman, L., \& Zuckerman, V. (1982). Parenting exceptional children. Individual Psychology, 38, 398-403. 